\title{
HOW COMPANIES USE OPEN SOURCE SOFTWARE IN THE VOICE OVER INTERNET PROTOCOL MARKET
}

\author{
By \\ Azmat Khan \\ A thesis submitted to the Faculty of Graduate Studies and Research \\ in partial fulfillment of the requirements for the degree of \\ Master of Engineering in Telecommunications Technology Management \\ Department of Systems and Computer Engineering \\ Carleton University \\ Ottawa, Canada, K1S 5B6
}

September 2006

(C) Copyright 2006 Azmat Khan 


$\begin{array}{ll}\begin{array}{l}\text { Library and } \\ \text { Archives Canada }\end{array} & \begin{array}{l}\text { Bibliothèque et } \\ \text { Archives Canada }\end{array} \\ \begin{array}{l}\text { Published Heritage } \\ \text { Branch }\end{array} & \begin{array}{l}\text { Direction du } \\ \text { Patrimoine de l'édition }\end{array} \\ \begin{array}{l}\text { 395 Wellington Street } \\ \text { Ottawa ON K1A ON4 }\end{array} & \begin{array}{l}\text { 395, rue Wellington } \\ \text { Ottawa ON K1A ON4 } \\ \text { Canada }\end{array}\end{array}$

Your file Votre référence ISBN: 978-0-494-33678-6 Our file Notre référence ISBN: 978-0-494-33678-6

NOTICE:

The author has granted a nonexclusive license allowing Library and Archives Canada to reproduce, publish, archive, preserve, conserve, communicate to the public by telecommunication or on the Internet, loan, distribute and sell theses worldwide, for commercial or noncommercial purposes, in microform, paper, electronic and/or any other formats.

The author retains copyright ownership and moral rights in this thesis. Neither the thesis nor substantial extracts from it may be printed or otherwise reproduced without the author's permission.
AVIS:

L'auteur a accordé une licence non exclusive permettant à la Bibliothèque et Archives Canada de reproduire, publier, archiver, sauvegarder, conserver, transmettre au public par télécommunication ou par l'Internet, prêter, distribuer et vendre des thèses partout dans le monde, à des fins commerciales ou autres, sur support microforme, papier, électronique et/ou autres formats.

L'auteur conserve la propriété du droit d'auteur et des droits moraux qui protège cette thèse. $\mathrm{Ni}$ la thèse ni des extraits substantiels de celle-ci ne doivent être imprimés ou autrement reproduits sans son autorisation.
In compliance with the Canadian

Privacy Act some supporting forms may have been removed from this thesis.

While these forms may be included in the document page count, their removal does not represent any loss of content from the thesis.
Conformément à la loi canadienne sur la protection de la vie privée, quelques formulaires secondaires ont été enlevés de cette thèse.

Bien que ces formulaires aient inclus dans la pagination, il n'y aura aucun contenu manquant.

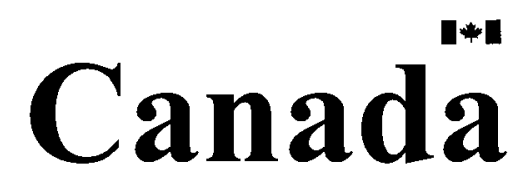




\section{ABSTRACT}

This research uses four theoretical perspectives to examine how nine open source companies used open source software in the voice over Internet Protocol (VoIP) market. The outcomes of this research include descriptions of nine open source companies, a timeline for the major events in the open source VoIP market, and insights from examining the data using the four theoretical perspectives. Research results suggest that open source VoIP companies started by addressing the needs of individuals who were nonconsumers of proprietary telephone systems. Initially, the open source market offers were of low quality, cheap, and low in functionality and features. As communities improved the performance and reliability of the open source offers they attracted small and medium size business customers and competed with proprietary offers. Successful open source companies compete and cooperate with proprietary companies. They sell commercial software and complementary assets and deliver services such as consulting, implementation, support, training and application management. This research will be of interest to entrepreneurs who wish to use open source VoIP because it will help them to know the market, players and value proposition. Results will also be of interest to academics studying open source software because it will help them to understand the market for open source VoIP products. 


\section{ACKNOWLEDGEMENTS}

I would like to thank my thesis supervisor Prof. Tony Bailetti for his invaluable guidance, support and encouragement in this study. He was a great help to materialize this research. I learnt a lot from him during this study in the field of scientific research.

A special thanks is also owed to Prof. John Callahan for his thorough guidance and feedback through out this study.

This thesis was developed as part of the Competing in open environments research program led by Tony Bailetti, Carleton University, and Peter Carbone, Nortel. The support received from Nortel for this research and the M.Eng. in Telecommunications Technology Management program is gratefully acknowledged. 


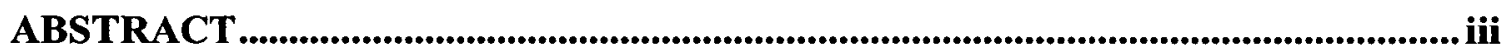

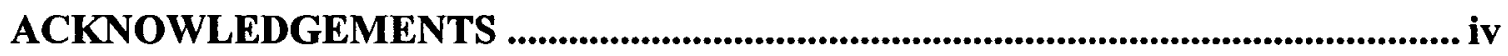

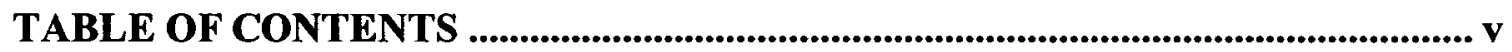

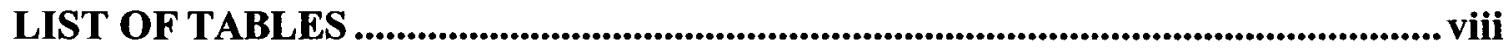

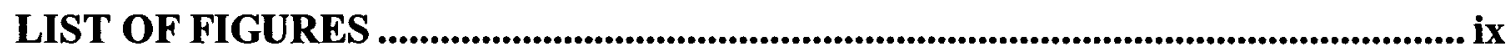

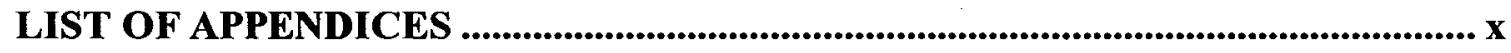

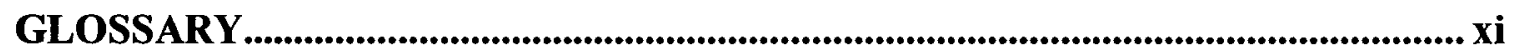

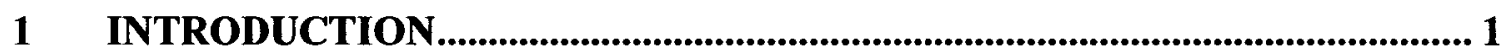

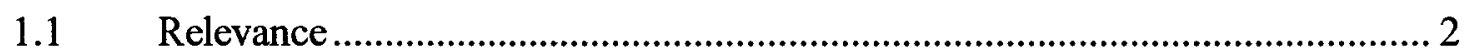

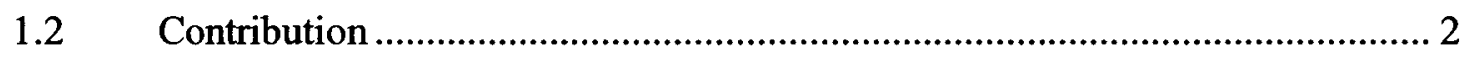

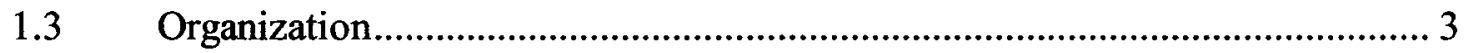

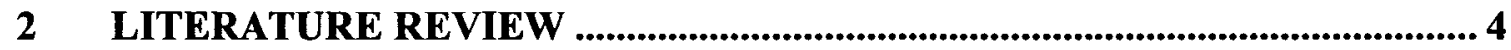

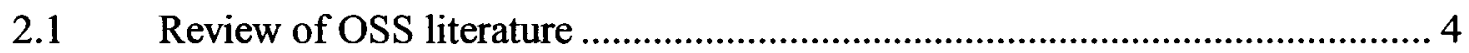

2.1.1 Motivations of individuals to participate in OSS projects ......................... 7

2.1.2 Motivations of companies to participate in OSS projects.......................... 8

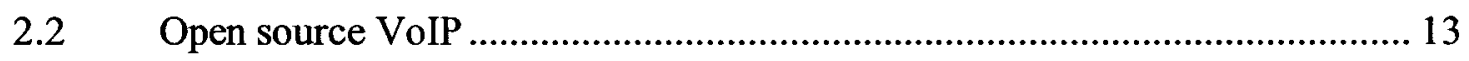

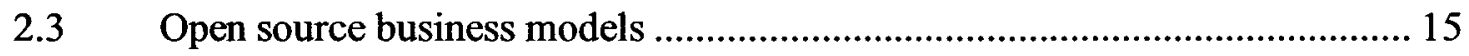

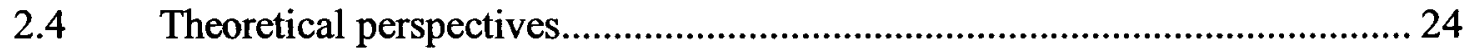

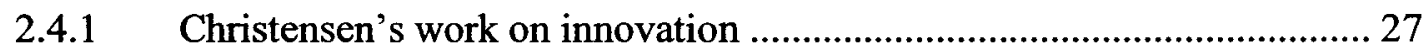

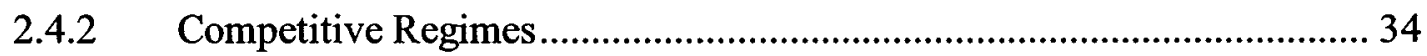

2.4.3 Commercialization Framework ............................................................ 35

2.5 Lessons Learned from the Literature Review ............................................ 38

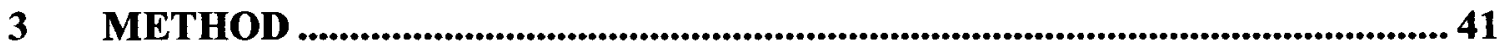




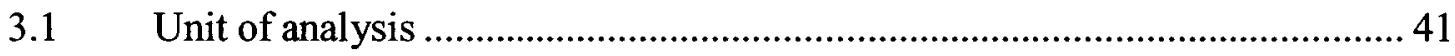

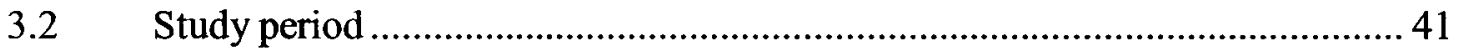

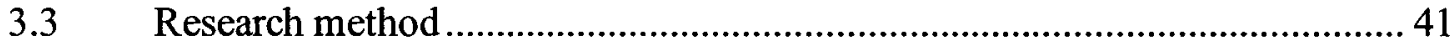

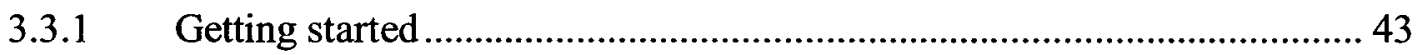

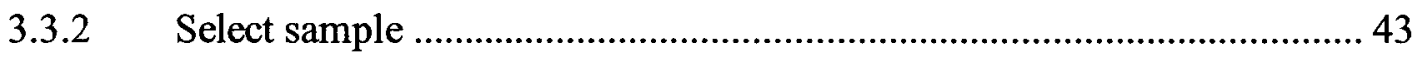

3.3.3 Select theoretical perspectives ................................................................... 43

3.3.4 Define data collection method .............................................................. 44

3.3.5 Collect data on companies and write cases............................................. 45

3.3.6 Collect data on open source projects ..................................................... 46

3.3.7 Data analysis and develop timeline

3.3.8 Data analysis and generate insights ............................................................ 46

4 WRITE UP OF COMPANIES INCLUDED IN THE SAMPLE...........................48

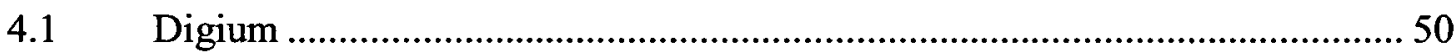

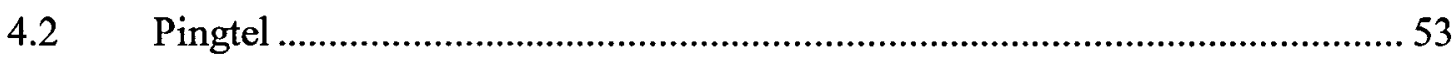

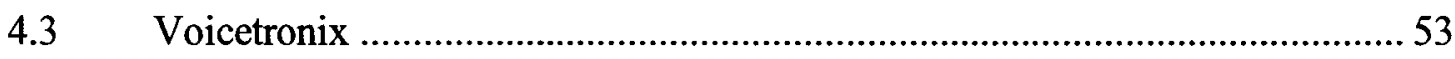

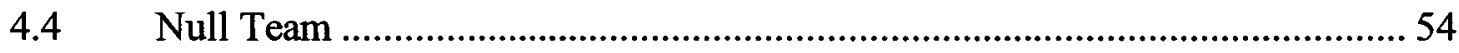

4.5 Tycho Softworks ..................................................................................... 55

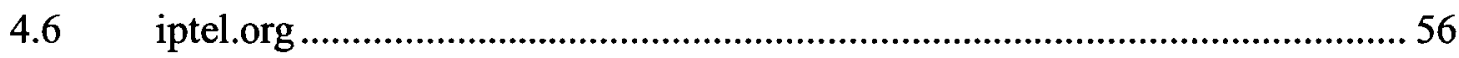

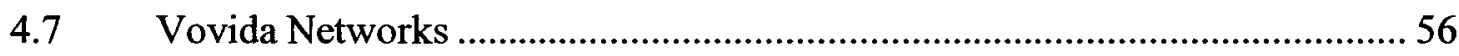

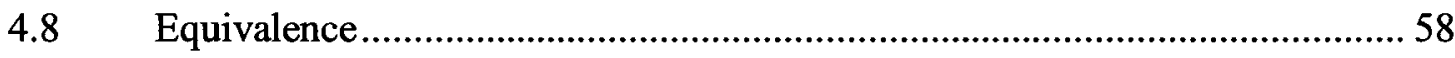

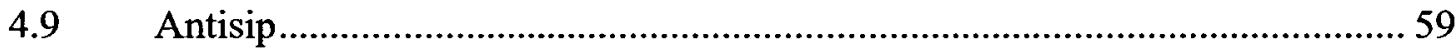

5 RESULTS

5.1 Timeline for the major events in the open source VoIP market ......................60 60

5.2 Comparing open source and proprietary VoIP PBX companies using disruptive technology and capabilities perspective............................................ 63

5.2.1 Competitive regimes for open source VoIP PBX identified....................... 64

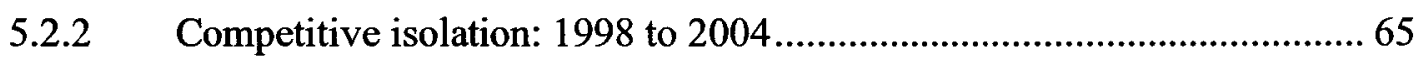

5.2.3 Competitive convergence: 2004 to February 2006 ................................... 67

5.3 Insights ...................................................................................................... 68 
5.3.1 Using the lenses of disruptive innovation theory and demand based

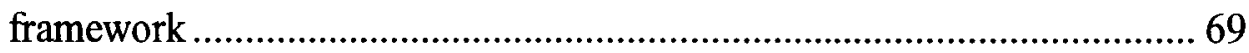

5.3.2 Using the lens of Gans and Stern's commercialization framework.......... 70

5.3.3 Using the lens of Teece's commercialization framework........................ 72

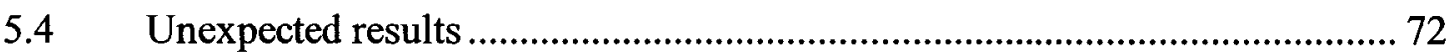

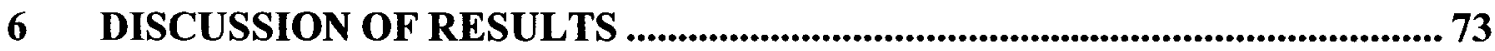

7 CONCLUSIONS, LIMITATIONS AND SUGGESTIONS FOR FUTURE

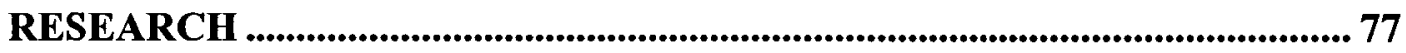

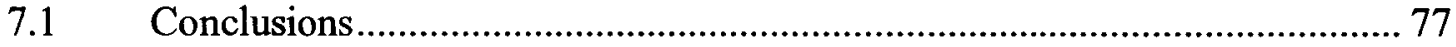

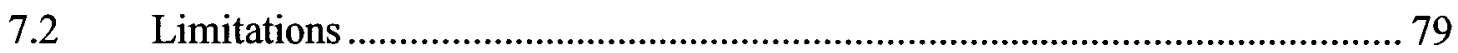

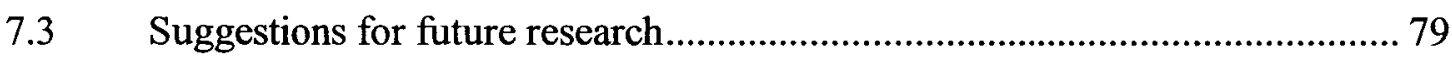

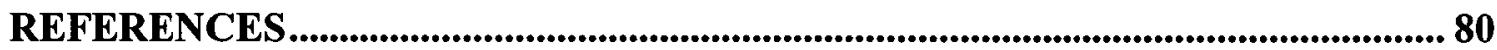

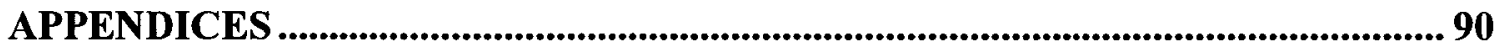

vii 


\section{LIST OF TABLES}

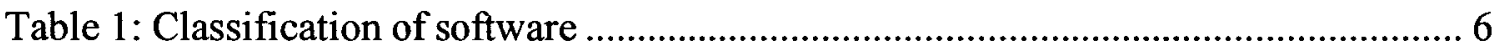

Table 2: Motivations to participate in OSS projects................................................ 9

Table 3: Literature on why companies participate in OSS projects................................ 13

Table 4: Means of appropriating returns from OSS....................................................... 21

Table 5: Seven approaches to generate revenue from OSS ......................................... 23

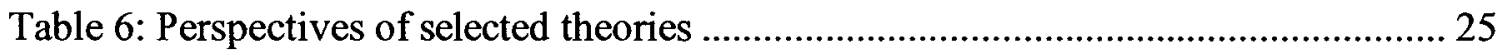

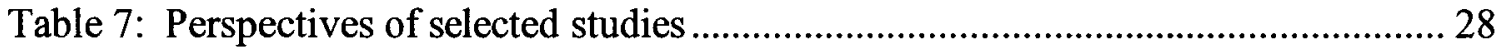

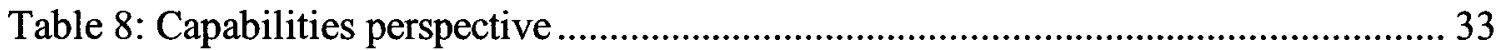

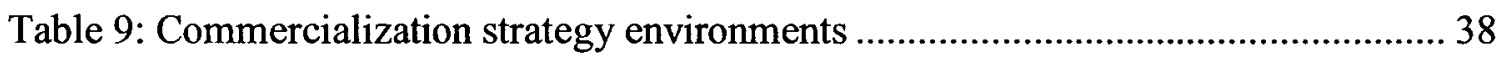

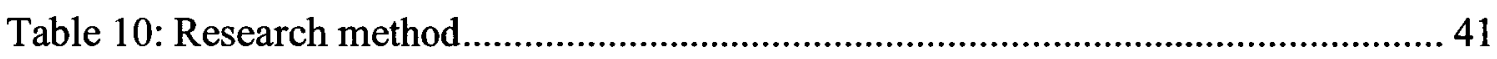

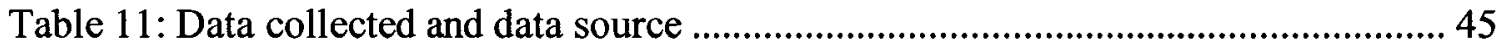

Table 12: Open source telephony companies included in the sample ............................. 48

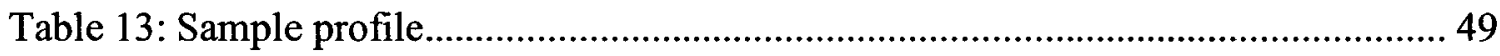

Table 14: Timeline for the major events in the open source VoIP market ......................60

Table 15: The 1998-2004 competitive isolation regime ........................................... 66

Table 16: The 2004-February 2006 competitive convergence regime ............................67

Table 17: Insights using disruptive innovation theory and demand based framework..... 69

Table 18: Insights using Gans and Stern's commercialization framework .................. 70

Table 19: Insights using Teece's commercialization frameworks................................. 72

Table 20: Insights using four theoretical perspectives............................................ 77 


\section{LIST OF FIGURES}

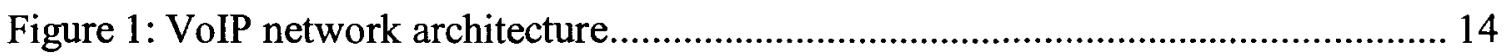

Figure 2: Software value chain for standard software versus individual software .......... 18

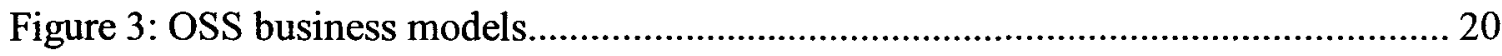

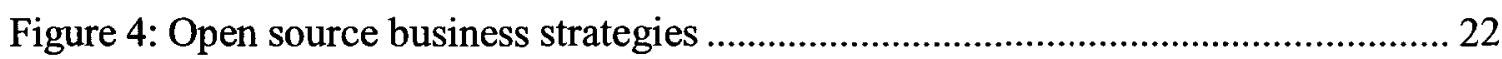

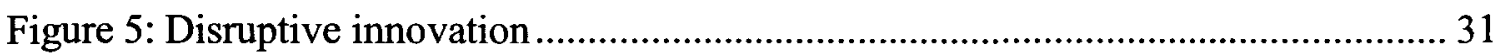




\section{LIST OF APPENDICES}

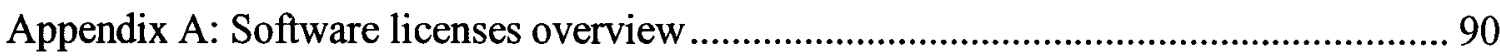

Appendix B: Background information of the open source VoIP companies................... 90

Appendix C: Business models of open source VoIP companies ................................... 92

Appendix D: Open source VoIP companies by the license of the open source projects

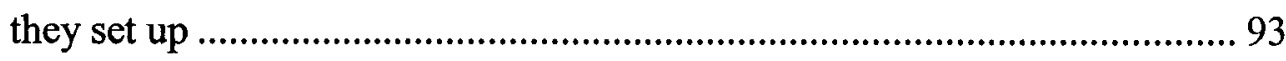




\section{GLOSSARY}

HW Hardware

IAX Inter-Asterisk eXchange

IP Internet Protocol

IVR Interactive Voice Response

OSS Open Source Software

PBX Private Branch eXchange

PSTN Public Switched Telephone Network

SER SIP Express Router

SME Small and Medium Enterprises

TDM Time Division Multiplex

TMT Top Management Team

VOCAL Vovida Open Communication Application Library

VoIP Voice over Internet Protocol

YATE Yet Another Telephony Engine 


\section{INTRODUCTION}

The research question is: how voice over Internet Protocol (VoIP) companies use open source software (OSS).

VoIP is a technology used to transmit voice traffic over public (e.g., Internet) and private data networks. To implement VoIP, network equipments such as communications server, media/messaging server, configuration management server, IVR/applications server, IP hard and softphones, and gateways are required. VoIP implementation also requires protocols such as: H.323, SIP, IAX among others. There are many companies who generate revenues by providing the various components for VoIP networks, including open source VoIP companies (Drew and Gallon, 2003).

For the purpose of this research, an open source VoIP company is a company that generates revenues from the sale of OSS related products and services to customers in the VoIP market. Open source VoIP companies combine in-house expertise with the inventive activity of the open source community to deliver marketable offers.

An OSS is a computer program with a distribution license that provides users the freedom to run the program for any purpose, to study and modify the program, and to redistribute copies of either the original or modified program without having to pay royalties to previous developers ${ }^{1}$ (Wheeler, 2005). An open source project refers to a project used to develop and release software under an open source license (Krogh and Hippel, 2003).

\footnotetext{
${ }^{1}$ For the widely accepted definition of OSS, see http://www.opensource.org/docs/definition.php.
} 
This research is the first to examine how companies use open source projects to capture value in the VoIP market using the constructs of four theoretical perspectives: disruptive innovation theory (Bower and Christensen, 1995; Christensen and Overdorf, 2000; Christensen, Johnson and Rigby, 2002), demand based framework (Adner, 2001; 2002), commercialization strategy framework (Gans, Hsu and Stern, 2002; Gans and Stern, 2003), and commercialization framework advanced by Teece (1986).

\section{$1.1 \quad$ Relevance}

The research is relevant for at least two reasons. First, entrepreneurs and top management teams of entrant and incumbent firms in the VoIP market will be interested in this research because it provides insights on how to use open source to compete.

The second reason this research is relevant is because academics studying the evolution of the markets for open source products will have concrete examples on open source companies operating in the VoIP market.

\subsection{Contribution}

This research makes three contributions:

1. Write ups of nine open source VoIP companies

2. A timeline for the major events in the open source VoIP market

3. Insights on how VoIP companies use OSS 


\subsection{Organization}

The thesis is organized into seven chapters. Chapter 1 is the introduction. Chapter 2 reviews the literature. Chapter 3 describes the research method. Chapter 4 provides the write ups of companies included in the sample. Chapter 5 provides the results obtained. Chapter 6 discusses the results. Finally, chapter 7 provides the conclusions, describes the limitations of this research, and makes suggestions for future research. 


\section{LITERATURE REVIEW}

This chapter is organized into four sections. Section 1 reviews the different literature streams on OSS. Section 2 discusses the open source VoIP. Section 3 discusses the business models used for generating value from OSS. Section 4 discusses the theoretical perspectives to be used for examining competition in the VoIP market.

\subsection{Review of OSS literature}

An OSS is governed by a license that permits anybody to access the source code, modify the software, and redistribute the software whether modified or unmodified (Open Source Initiative, 1998).

OSS projects can be classified into community-founded and spun-out projects (West and O’Mahony, 2005). One or more programmers start community-founded projects (Raymond, 1999a). Founders of some community-founded projects start companies to profit from the project. Spun-out projects have software that initially started as proprietary inside the company but then was released as open source software. Some companies continue to support the project by continuously providing resources.

Open source is the expression of a new means of production. Open source is a community of software developers who collaborate around a code commons. That code commons is then used by people to create wealth of one form or another, and in the process of doing that, because everyone is collaborating over a common pool of code, people naturally fix bugs and introduce new features into that pool of common code, enriching it in a way that benefits them, but also 
benefits everyone else in the community at the same time (Stern, Phipps and Hahn, 2006). Open source projects implement mechanisms to protect their work by enforcing copyrights, trademarks, and the license of the software (O'Mahony, 2003). Lerner and Tirole (2002) classify open source licenses into: highly restrictive, restrictive, and unrestrictive. The GNU (named for GNU's not Unix) General Public License (GPL) is an example of a highly restrictive license; the GNU Lesser General Public License (LGPL) is an example of a restrictive license; while the Berkeley Software Distribution (BSD) license is considered an unrestrictive license. Appendix A provides a comparison of open source licenses (Nissila, 2004).

In 1985, Richard Stallman, a programmer at the MIT, established the Free Software Foundation to develop and disseminate a wide variety of software without license fees (Lerner and Tirole, 2001). Stallman conceived a license scheme, named GPL, to prevent cooperatively developed software from turning into proprietary. Today a significant number of software programs are released under the GPL. Every program that uses a piece of GPLed code has to be released under the GPL too. The GPL license grants the licensee a large number of rights. However, the viral effect of OSS limits the diffusion of OSS in companies' software development organizations (Bonaccorsi, Rossi and Giannangeli, 2004).

In 1998, leaders of the open source community established the Open Source Initiative (OSI). They drafted a document, the Open Source Definition (OSD), containing the criteria that a software licence must meet to be labelled as open source. The "viral" effect of the GPL is not a requirement for OSD-approved licenses. Moreover OSI recast the expression 'free software', chosen by Stallman, as 'open source'. Eric Raymond and Bruce Perens were the key people who 
drove this effort. Their aim was to promote OSS for commercial use because they believed that both the free/open source community and the business world could benefit from the wide dissemination of OSS (Wheeler, 2005).

Availability of source code and price can be used to classify software (Spiller and Wichmann, 2002). Table 1 classifies software based on whether or not the software is open and whether or not the sofware is free.

Table 1: Classification of software

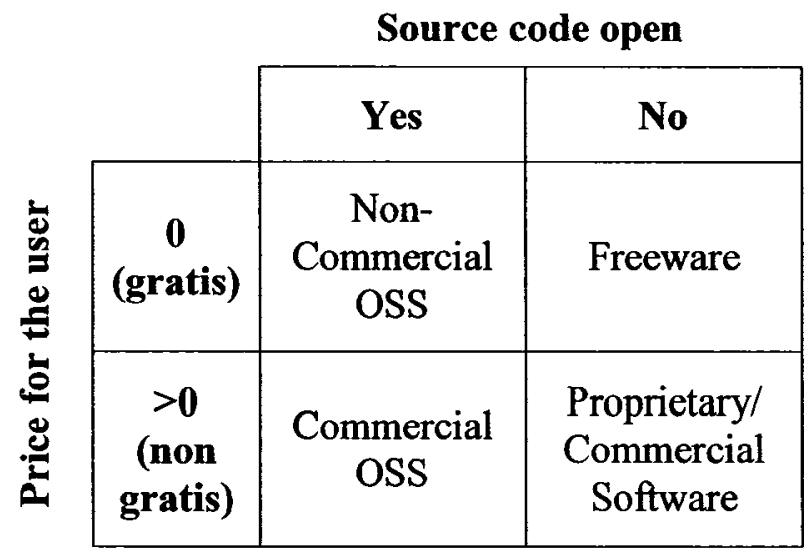

Source: Spiller and Wichmann, 2002

Studies have examined open source projects' choice of licenses (Lerner and Tirole, 2002; O'Mahony, 2003). They found that most projects use restrictive and highly restrictive licenses to protect the future of the project by taking away the incentive to evolve open source software into proprietary software. 
OSS is best suited for technically proficient users (such as Internet service providers) with strong motivations for customization than non-technical users.

An example of a benefit provided by open source is the provision of complementary assets. Typically, the provision of applications for an operating system is controlled by formal, published interfaces. However, in an open source system, a third-party software supplier can add its own interfaces as needed to provide functionality unanticipated by the original author of the open source system.

Another benefit of open source systems is their increased quality. A widely distributed community of user-programmers work to debug the software. This debugging activity is important. Volunteer labor finds and corrects errors and gaps in open source systems.

The major reason open source projects fail is because they do not attract experienced developers to do the work. Sponsors of open source projects (whether organizations or individuals) face an important challenge, they must attract enough of the right sort of users to improve the quality and features of the software.

\subsubsection{Motivations of individuals to participate in OSS projects}

Individual developers are motivated to participate in OSS projects for several reasons. They participate to solve their own programming problems - scratch an itch (Raymond, 1999a) or satisfy their own needs (Franke and von Hippel, 2003). While most of these volunteers do not get paid for their contributions, others are paid (Hars and Ou, 2002; Hertel, Niedner, and Herrmann, 
2003). Other developers participate as a "signaling" method (Lerner and Tirole, 2001), that is, to gain reputation among peers and to showcase their skills for future employment opportunities. Some developers participate for the learning opportunity and to sharpen their programming skills (Lakhani and Von Hippel, 2003).

In OSS projects, developers are also users (Raymond, 1999b). They develop, test, use and support other users (Lakhani and von Hippel, 2003). As the OSS project becomes popular and more users become involved, problems are quickly fixed (Raymond, 1999b). Since users have access to the source code, it is easy to detect and fix bugs that they encounter (Franck and Jungwirth, 2003). Krishnamurthy (2002), though, found that a small group of developers tend to contribute the most to an OSS project.

\subsubsection{Motivations of companies to participate in OSS projects}

Companies participate in OSS projects for motives that are different from the motives that drive developers to participate in OSS projects. Companies are motivated to participate so they can better know the competition, incorporate open source ideas into their products, and hire talented programmers (Lerner and Tirole, 2001).

Bonnaccorsi and Rossi (2004) classified the motivations that individuals and companies have to participate in OSS projects into three areas: economic, social, and technological. Table 2 provides the Bonnacorsi and Rossi classification. 
Companies invest significant amount of resources in open source. IBM claims to have spent $\$ 1$ billion on Linux alone (Wilcox, 2000). Other companies also devote significant resources to the development of open source software (Wichmann, 2002).

\begin{tabular}{|c|c|c|}
\hline Motivation Area & Individuals & Companies \\
\hline Economic & $\begin{array}{l}\text { - Monetary rewards } \\
\text { - Low opportunity costs } \\
\text { - Gaining reputation } \\
\text { among peers } \\
\text { - Gaining future career } \\
\text { benefits }\end{array}$ & $\begin{array}{l}\text { - Being independent of the price } \\
\text { and license policies of the large } \\
\text { software companies } \\
\text { - Addressing the new model of } \\
\text { software as a consumer-driven } \\
\text { service (making money on } \\
\text { complementary services) } \\
\text { - Obtaining indirect revenues by } \\
\text { selling related products } \\
\text { - Affording innovation (by } \\
\text { exploiting the R\&D activity of } \\
\text { the open source community) } \\
\text { - Hiring good IT specialists }\end{array}$ \\
\hline
\end{tabular}




\begin{tabular}{|c|c|c|}
\hline Social & $\begin{array}{l}\text { Fun to program (loving } \\
\text { to code) } \\
\text { - Altruism (gift economy) } \\
\text { - Sense of belonging to the } \\
\text { community } \\
\text { - Fight against proprietary } \\
\text { software }\end{array}$ & $\begin{array}{l}\text { - Conforming to the values of the } \\
\text { open source community (in order } \\
\text { not to betray the trust of the open } \\
\text { source developers) } \\
\text { - Sharing code and knowledge } \\
\text { with the community } \\
\text { (reciprocating in order to sustain } \\
\text { cooperation) } \\
\text { Thinking that software should } \\
\text { not be a proprietary good (in } \\
\text { order to reduce market power of } \\
\text { large companies) }\end{array}$ \\
\hline Technological & $\begin{array}{l}\text { - Learning } \\
\text { - Contributions and } \\
\text { feedback from the } \\
\text { community } \\
\text { - Working with bleeding- } \\
\text { edge technology } \\
\text { - Scratching a personal } \\
\text { itch }\end{array}$ & $\begin{array}{l}\text { Exploiting feedback and } \\
\text { contributions from developers of } \\
\text { the open source community for } \\
\text { cutting development costs and } \\
\text { improve the software } \\
\text { - Exploiting feedback and } \\
\text { contributions from the user } \\
\text { community for testing and } \\
\text { improving software } \\
\text { - Cutting hardware costs } \\
\text { - Adomoting standardization } \\
\text { Addressing security issues }\end{array}$ \\
\hline
\end{tabular}

Companies that have undisputed rights to the open source software are able to charge license fees (Dahlander, 2004). These companies institute two types of licenses to their software: an open source and commercial license. 
Companies add value by assembling and testing the software rigorously then selling support contracts, warranty, and integration services (Raymond, 1999a; Pal and Madanmohan, 2003). They build expertise in the open source software and charge customers for customization services tailoring the software to customers' specific needs (van Wendel de Joode et al., 2002). Another way companies make money is through subscription services. Companies provide software maintenance, upgrades, and updates to customers subscribed to the service (Koenig, 2004).

Due to the chaotic nature of open source development, companies buffer their customers by creating delivery schedules that coincide with the customer's timelines (van Wendel de Joode et al., 2002). Companies make sure that the OSS version the customers use is stable and welltested. The company takes a snapshot of the development version maintained by the OSS project. The company tests and fixes the problems found on this snapshot. The tested stable version plus add-on services is then offered to customers for a fee while the fixes are contributed back to the project.

Some companies participate in OSS projects for strategic reasons. Companies participate to gain a market position in a complementary segment, jumpstart an infant market, or break into an existing market with entrenched proprietary software (Raymond, 1999a; Bonaccorsi and Rossi, 2003). Bonnacorsi and Rossi (2003) found that Linux systems have managed to diffuse in environments dominated by Microsoft's Windows NT. 
Another reason for particpating in OSS projects is to establish a standard or dominant design to preempt rivals from establishing a competing standard and dominant design (Raymond, 1999c; Henkel, 2003; Dahlander, 2004). Koenig (2004) provided IBM as an example of adopting the Apache web server while dropping its own web server to prevent Microsoft from monopolizing the web server market.

Other companies participate in OSS projects to commoditize complementary products (Koenig, 2004) and downstream suppliers (Raymond, 1999c). IBM is an example of supporting Linux to commoditize the x86-operating system, creating an opportunity by offering value higher up the software stack. The company makes money by offering clustering, availability, provisioning, and management software (Koenig, 2004).

Another reason companies participate in OSS projects is to lower their cost by taking advantage of pooled R\&D especially for non-essential software (West and Gallagher, 2004). West and Gallagher (2004) gave examples such as Linux and Mozilla as software that benefited from pooled $R \& D$. Companies donate $R \& D$ to the open source project while exploiting the skills of all contributors and to sell related products.

Table 3 provides a summary of literature on why companies participate in open source. 
Table 3: Literature on why companies participate in OSS projects

- Make money through:

○ dual license (Valimaki, 2003; van Wendel de Joode et al., 2002;

Dahlander, 2004)

- selling of complements (van Wendel de Joode et al., 2002; Raymond, 1999; Dahlander, 2004; Lerner and Tirole, 2000)

○ providing consulting service, support, and warranty (Pal and Madanmohan, 2002; Raymond, 1999a; van Wendel de Joode et al., 2002; Koenig, 2004; Dahlander, 2004)

- Jumpstart an infant market, grow market, or enter market with entrenched proprietary players (Raymond, 1999b; Bonaccorsi and Rossi, 2003)

- Establish as standard or preempt a standard (Raymond, 1999c; Henkel, 2003; Dahlander, 2004)

- Commoditize complements and value chain (Raymond, 1999c; Koenig, 2004)

- Lower cost through pooled R\&D (West and Gallagher, 2004)

\subsection{Open source VoIP}

Today's communications market is in a considerable flux caused by major ongoing changes in the technology of core products and the network infrastructure (Sulkin, 2002). The rapid replacement of circuit switches in telephony by the VoIP also gave rise to a new phenomenon, open source VoIP. Several open source communities have emerged to develop open source VoIP software, such as Asterisk and SIPfoundry, companies that develop VoIP PBXs. The VoIP software developed by these communities is free to download and use under the various kinds of open source licenses. There are also companies that came up with their unique business models to generate revenue from open source VoIP applications, such as Digium that deals in open source VoIP PBX. Besides the communities for VoIP PBXs, there are other communities which develop various components for the open source VoIP such as YATE (Yet Another Telephony 
Engine) works on softswitch, Bayonne works on IVR (Interactive Voice Response) platform, SER (SIP Express Router) works on SIP (Session Initiation Protocol) server, VOCAL (Vovida Open Communication Application Library) works on telephony application server, OpenH323 works on H.323 library, and oSIP (open-source SIP) works on SIP library ${ }^{2}$. This study will concentrate on the open source projects which are being commercially exploited.

VoIP can be deployed in many different network segments. It was first deployed in the backbone and enterprise networks, but now VoIP is being deployed in the end-to-end network solutions Drew and Gallon (2003). Figure 1 provides a VoIP network architecture.

Figure 1: VoIP network architecture

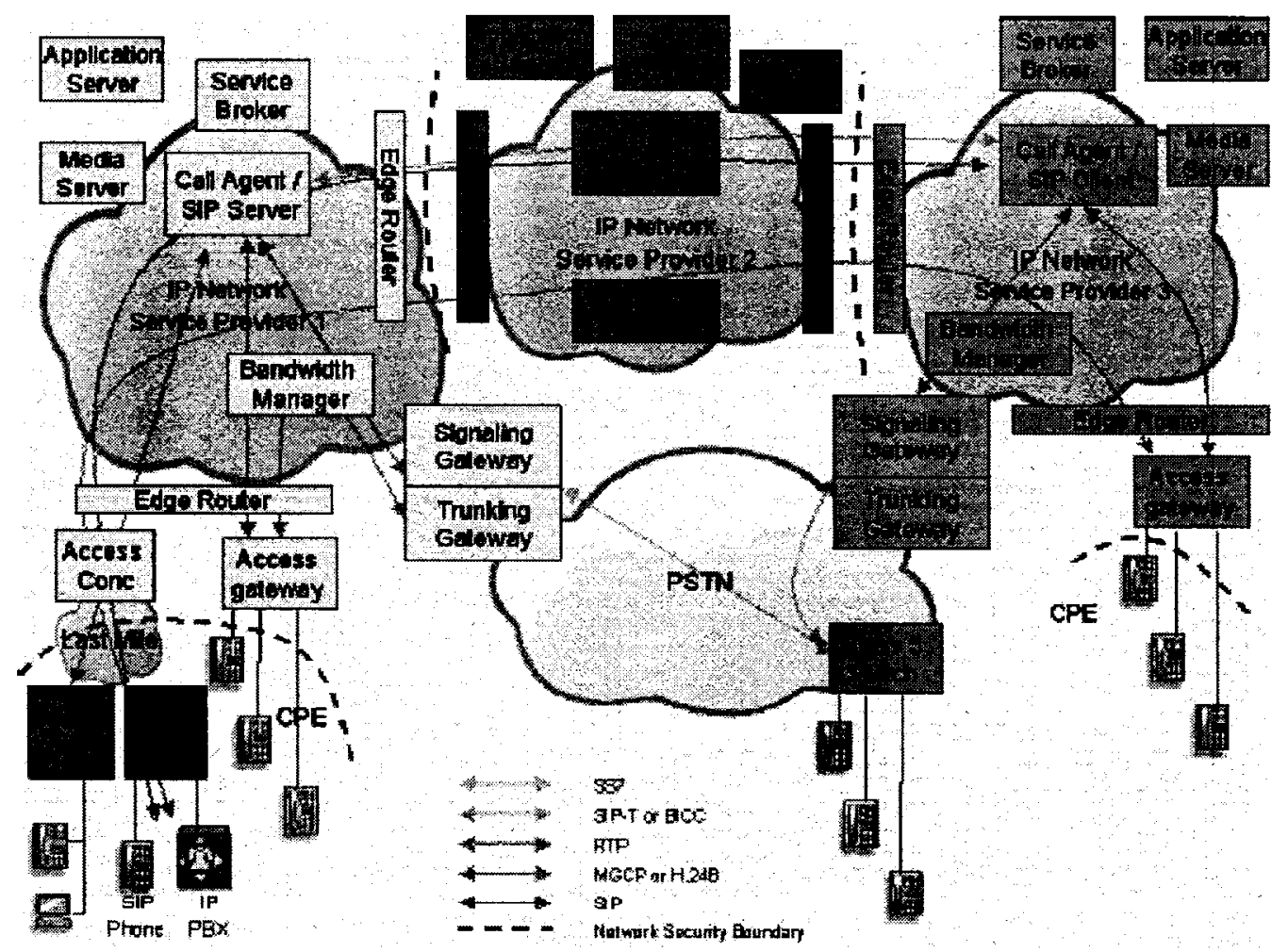

Source: Drew and Gallon (2003)

\footnotetext{
${ }^{2}$ voip-info.org portal
} 
Open source VoIP projects are targeting various segments of the VoIP infrastructure shown above. To date, the OSS projects launched are targeting VoIP PBXs, different protocol suites (SIP, H.323, MGCP and RTP), softphones, different gateways, application server and call agent/SIP server ${ }^{3}$.

\subsection{Open source business models}

A business model can be defined as what a business does and how a business makes money doing those things (Weill et al., 2005). Business model emerged and widely spread during the Internet booming time (Magretta, 2002). Chesbrough and Rosenbloom (2003) investigated the role of business models in capturing value from technological innovation in Xerox's technology spin-off companies. They identified six key functions of a successful business model:

1. Articulate the value proposition, i.e., the value created for customers with technological solutions

2. Identify a market segment, i.e., the users to whom the technology is useful and for what purpose, and specify the mechanisms for generating revenues

3. Define the structure of the value chain required to create and distribute the offering, and determine the complementary assets needed to support the company's position in the value chain

4. Estimate the cost structure and profit potential of developing the products, based on the chosen value proposition and value chain structure

5. Describe the position of the company within the value network linking suppliers and customers, including identification of potential partners and competitors

\footnotetext{
${ }^{3}$ voip-info.org portal
} 
6. Formulate the competitive strategy by which the innovating company will gain and hold competitive advantage over competitors

Chesbrough and Rosenbloom (2003) conclude that a business model provides a coherent framework that takes technological characteristics and potentials as inputs, and converts them through customers and markets into economic outputs. A business model is a construct that mediates between technology innovations and economic value creation.

Magretta (2002) explained the importance of a business model in determining the success or failure of a business. She also explained the differences between business models and strategy, and discussed some important issues managers need to be aware of when defining a business model. Her work provides some practical guidelines for business managers to use business models.

The main characteristic of OSS is that the users can freely use, modify and redistribute the software. However, there is a rich landscape of OSS licenses, which differ in terms of right for commercial use and other aspects. The most important OSS license is GPL. A vendor's decision to disclose technology under GPL license is a waiver of its ability to appropriate returns from that technology. The use of non-GPL licenses suggests that proprietary vendors are aware of the competitive risks of such an appropriability waiver and are thus experimenting to find the right compromise between totally proprietary platforms and totally open ones. So far, the two hybrid strategies have been: 
- Opening parts-waving control of commodity layer(s) of the platform, while retaining full control of other layers that presumably provide greater opportunities for differentiation

- Partly open-disclosing technology under such restrictions that it provides value to customers while making it difficult for it to be directly employed by competitors

The former strategy of releasing code under GPL is important as an offensive strategy to speed adoption of a new standard or a particular implementation of such a standard. Waiving intellectual property rights makes the standard (or implementation) more attractive to competitors and key users, priming the positive feedback bandwagon effects that can accrue to early market leaders. It also increases the number of products that are interoperable with the vendor's products, particularly important for networking and other communications standards.

Spiller and Wichmann (2002) developed a taxonomy for the business models to appropriate returns from OSS. They distinguish between the product and the service side of the software market and position the firms' open source activities at different levels of the software value chain. The services surrounding software products range from consulting, implementation, support, and training to application management. 
Figure 2: Software value chain for standard software versus individual software

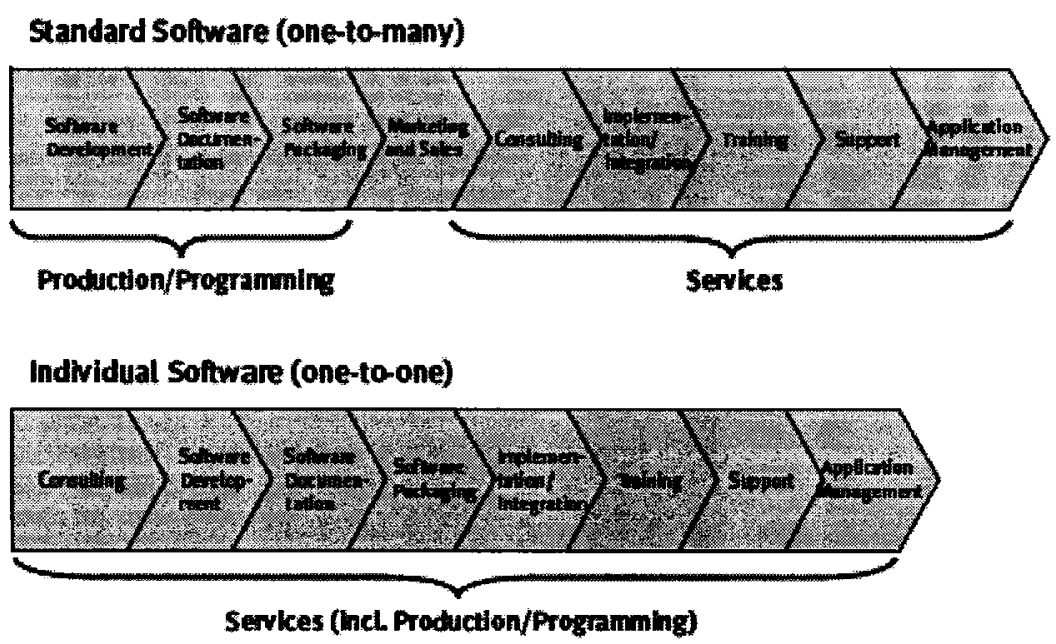

Source: Spiller and Wichmann (2002)

The firms on the product side of the OSS aggregate, integrate and optimize the OSS software that is freely downloadable from the Internet. These activities add significant value and convert raw software fragments in a ready to install software, usually supplied on a CD ROM together with documentation. Projects' evolution and social dynamics are the critical factors of this business model and firms must commit to coordinate individual developers, release the product on time and not forego the production. Linux distributors are probably the best-known firms in the product side (Spiller and Wichmann, 2002).

Distributors cover two market segments: First, the mass market with standardised packages offered to SMEs and private consumers. Second, the market for individual solutions, which are offered to medium to large corporate customers. The solutions market is completely different from the mass market. Most of the distributors consider the solution business as increasing and profitable income stream. Some of them cover the solutions market through partnerships with consulting companies. Due to their software knowledge from packaging and optimising the 
different software parts, the distributors certainly have the OSS as well as technical competence to build up consulting and service business. But it is in question whether they already have the know-how in consulting and business processes to become serious competitors for existing generalized IT service or consulting firms.

Open source distributions are sold by retailers, often together with other open source related materials, such as books or gadgets. This business model (accessorizing business model) has been successfully set up by O'Really and Associates, which publishes books that document and explain many open source program (Wichmann, 2002).

The provision of services as consulting, implementation, integration, support, training and application management for open source products is the heir to the for-profit business based on treating software as intellectual property. Service provision is made effective not only by big distributors but above all, it is the core business of small enterprises that target the private and SMEs market (Hecker, 2000).

Many companies operate in more than one field, for example the distributors. Although their main business is packaging, marketing and distribution of products, a major portion of their income is based on additional services such as consulting and support. Figure 3 below provides an overview of the existing business models. 
Figure 3: OSS business models

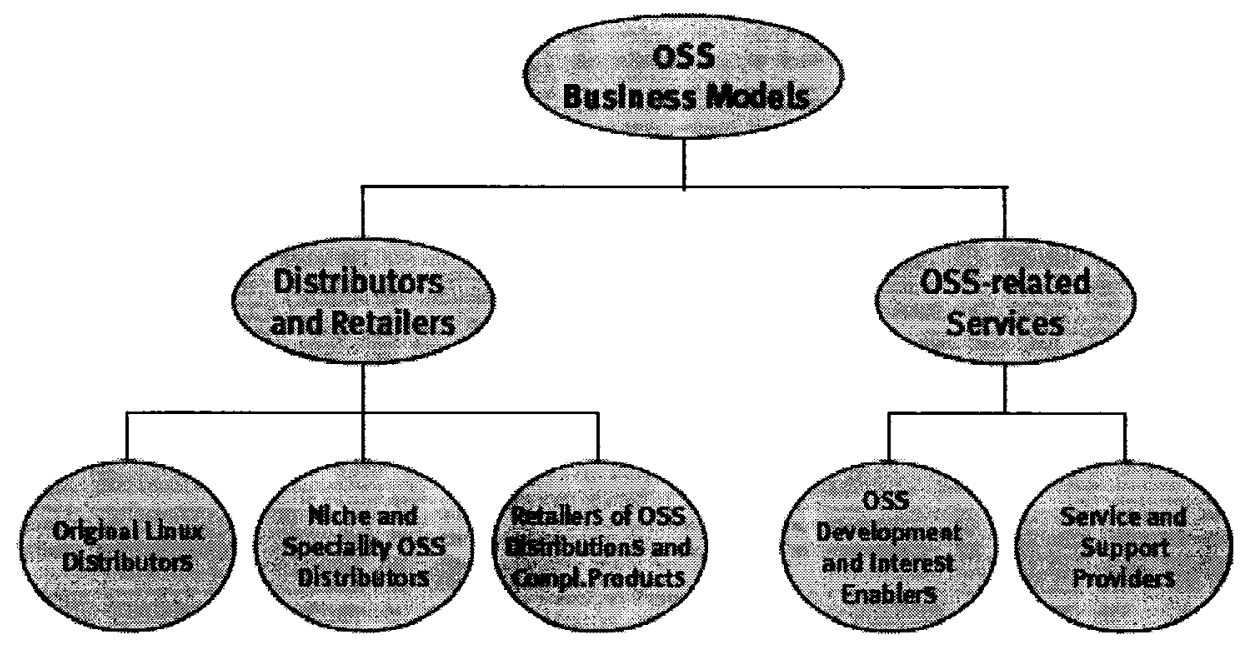

Source: Spiller and Wichmann (2002)

The reduction of development costs is the main competitive advantage of open source firms. Feedbacks and contributions of the open source community lower developing costs so that the costs of the first copy of software program decreases (Spiller and Wichmann, 2002).

Dahlander (2004) discussed the ways by which firms appropiate returns from OSS. Table 4 outlines the main categories - products and services - and the respective subcategories. 
Table 4: Means of appropriating returns from OSS

\begin{tabular}{|c|c|c|}
\hline Category & Sub-categories & Explanation of how it works in OSS \\
\hline \multirow[t]{2}{*}{ Products } & Licensing & $\begin{array}{l}\text { Licensing the right to use the software i.e. adding a } \\
\text { proprietary part to the open code or by allowing the } \\
\text { customer to use the source code how they wish }\end{array}$ \\
\hline & Black-box & Bunching several pieces of OSS in a hardware solution \\
\hline \multirow[t]{3}{*}{ Services } & Consultancy & $\begin{array}{l}\text { Consultancy work based on an area of expertise, be it a } \\
\text { product that the firm release or a community established } \\
\text { project }\end{array}$ \\
\hline & Education & $\begin{array}{l}\text { Education based on an area of expertise, be it a product that } \\
\text { the firm release or a community established project. }\end{array}$ \\
\hline & Support & $\begin{array}{l}\text { Support based on an area of expertise, be it a product that } \\
\text { the firm release or a community established project. }\end{array}$ \\
\hline
\end{tabular}

Source: Dahlander (2004)

Figure 4 illustrates the open source business strategies identified by Stern, Phipps and Hahn (2006): dual licensing, subscription, hosted, consulting, embedded, and stewardship. 
Figure 4: Open source business strategies

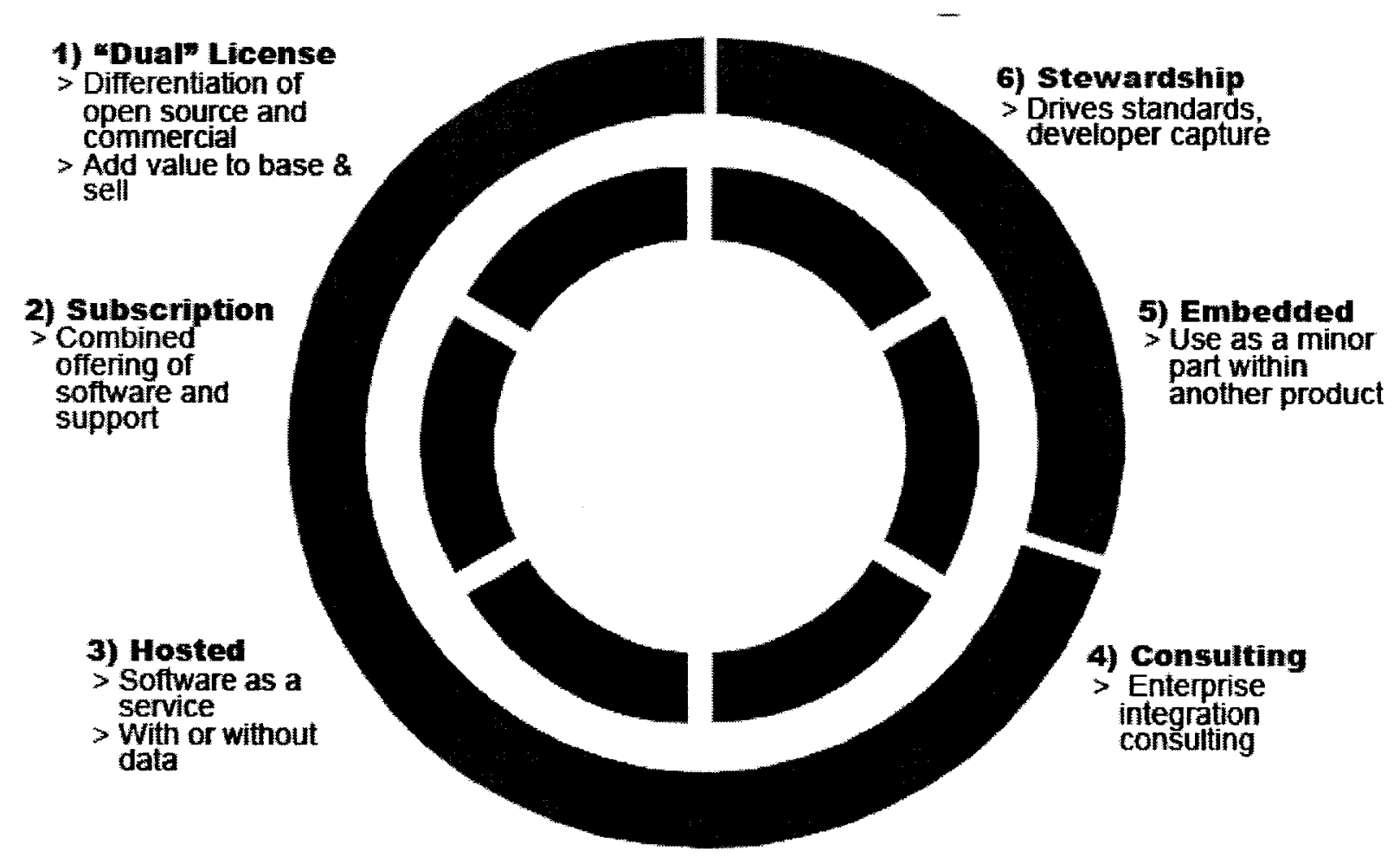

Source: Stern, Phipps and Hahn (2006)

According to Koening (2004), there are seven open source business strategies for competitive advantage - the optimization strategy, the dual license strategy, the consulting strategy, the subscription strategy, the patronage strategy, the hosted strategy and the embedded strategy.

Dahlander (2004) conducted a multiple case study on the approaches small open source companies used to appropriate returns from open source projects. He identified five major approaches of creating revenues using OSS: (1) consultancy, providing domain expertise in certain areas; (2) education; (3) support (e.g., installation, upgrading and trouble shooting); (4) licensing, adding a proprietary part to the open source product, or providing a commercial 
license for the open source code that allows its use in proprietary products; and (5) black-box, the packaging software products in hardware solutions.

Table 5 shows the approaches companies use to generate revenue from open source identified by Raymond (1999a).

Table 5: Seven approaches to generate revenue from OSS

\begin{tabular}{|l|l|}
\hline Approach & \multicolumn{1}{|c|}{ Description } \\
\hline $\begin{array}{l}\text { Loss-Leader/Market } \\
\text { Positioner }\end{array}$ & $\begin{array}{l}\text { Using OSS to obtain a market position for proprietary } \\
\text { software that generates direct revenue }\end{array}$ \\
\hline Widget Frosting & $\begin{array}{l}\text { Hardware manufacturers providing software as OSS while } \\
\text { selling hardware to generate revenue }\end{array}$ \\
\hline $\begin{array}{l}\text { Give Away Recipe, } \\
\text { Open a Restaurant }\end{array}$ & $\begin{array}{l}\text { Providing services rather than software products to generate } \\
\text { revenue }\end{array}$ \\
\hline $\begin{array}{l}\text { Accessorizing } \\
\text { Free the Future, Sell } \\
\text { the Present }\end{array}$ & $\begin{array}{l}\text { Providing accessories for OSS products, such as CDs, books. } \\
\text { to open the source code in the near future }\end{array}$ \\
\hline $\begin{array}{l}\text { Free the Software, while promising } \\
\text { Sell the Brand }\end{array}$ & $\begin{array}{l}\text { Providing OSS products for free, while retaining an } \\
\text { examination suite or set of compatibility criteria, then selling } \\
\text { users a brand certifying that their implementation of the } \\
\text { technology is compatible with all others wearing the brand }\end{array}$ \\
\hline $\begin{array}{l}\text { Free the Software, } \\
\text { Sell the Content }\end{array}$ & $\begin{array}{l}\text { Providing software for free, while selling subscriptions to } \\
\text { contents for profit }\end{array}$ \\
\hline Source: Raymond (1999a)
\end{tabular}

Bonaccorsi et al. (2004) studied the business models of open source companies, as well as their strategies. They focused on the hybrid business models adopted by many open source companies. In a hybrid business model, a company provides both open source and proprietary 
software products using different types of licensing schemes. They conducted a large-scale survey in Italian open source companies and obtained the empirical results of how the characteristics of OSS production mode and network externalities shape the strategies of new OSS entrants.

\subsection{Theoretical perspectives}

Table 6 identifies the key points of the four perspectives used in this study:

1. Disruptive innovation theory (Bower and Christensen, 1995; Christensen and Overdorf, 2000; Christensen, Johnson and Rigby, 2002)

2. Demand based framework (Adner, 2001; 2002)

3. Commercialization strategy framework (Gans, Hsu and Stern, 2002; Gans and Stern, 2003)

4. Commercialization framework (Teece, 1986, 1988) 
Table 6: Perspectives of selected theories

\begin{tabular}{|c|c|}
\hline Theory & Key points \\
\hline $\begin{array}{l}\text { innovation } \\
\text { theory } \\
\text { (Bower and } \\
\text { Christensen, } \\
\text { 1995; } \\
\text { Christensen and } \\
\text { Overdorf, 2000; } \\
\text { Christensen, } \\
\text { Johnson and }\end{array}$ & $\begin{array}{l}\text { The technological changes that damage established companies are } \\
\text { usually not radically new or difficult from a technological point of view. } \\
\text { - Established companies usually choose to go up-market with sustaining } \\
\text { technologies and enter market segments whose profit margins are high. } \\
\text { - It's difficult to divert resources from known customer needs in } \\
\text { established markets to markets and customers that seem insignificant or } \\
\text { do not exist } \\
\text { - Once the entrant companies have secured a foothold in the market and } \\
\text { improved the performance of their products, they aim at the established } \\
\text { markets above them. } \\
\text { - Successful disruptive innovators always target customers who welcome } \\
\text { simple products. } \\
\text { - Once a viable disruptive growth strategy has been defined, three classes } \\
\text { of factors - resources, processes and values need to be managed } \\
\text { carefully. } \\
\text { - Company's resources, processes and values determine its actions in the } \\
\text { market. } \\
\text { - When the product is not good enough, being an integrated company is } \\
\text { critical to success. } \\
\text { Once a modular architecture and the requisite industry standard have } \\
\text { been defined, the integration is no longer crucial to a company's } \\
\text { success. }\end{array}$ \\
\hline $\begin{array}{l}\text { Demand based } \\
\text { framework } \\
\text { (Adner, 2001; } \\
\text { 2002) }\end{array}$ & $\begin{array}{l}\text { - Lower marginal costs, higher volume and consequent lower prices } \\
\text { causes disruption. } \\
\text { - A consumer's perceived quality of a product, which play a critical role } \\
\text { in disruption, depends on how he values its mix of attributes. These } \\
\text { perceived quality levels shift with consumer preferences, along with }\end{array}$ \\
\hline
\end{tabular}




\begin{tabular}{|c|c|}
\hline & $\begin{array}{l}\text { other factors such as the extent of consumers' decreasing marginal } \\
\text { utility from product improvement. } \\
\text { - Consumers' preferences overlap and symmetry between segments is a } \\
\text { major determination of the disruptiveness of a product. } \\
\text { - The defining feature of a market segment is that all consumers in the } \\
\text { segment have the same perceived quality for a given product, while } \\
\text { quality perceptions may vary across segments. Thus, segments capture } \\
\text { horizontal differentiation. Within segments, consumers vary in their } \\
\text { willingness-to-pay for quality as in a standard model of vertical } \\
\text { differentiation. } \\
\text { - Three distinct competitive regimes arise under varying configuations of } \\
\text { demand: competitive isolation, competitive convergence, and } \\
\text { competitive disruption. } \\
\text { As the overlap between market segments' preferences increases, firms } \\
\text { have greater incentives to enter rivals' markets. } \\
\text { technology is therefore relevant to a larger number of consumers, has } \\
\text { greater incentive to invade, trading price for volume }\end{array}$ \\
\hline $\begin{array}{l}\text { Commercializati } \\
\text { on strategy } \\
\text { framework } \\
\text { (Gans, Hsu and } \\
\text { Stern, 2002; }\end{array}$ & $\begin{array}{l}\text { - Interaction between the excludability and complementary asset } \\
\text { environment define four distinct commercialization environments. } \\
\text { - When intellectual property protection is strong and important, } \\
\text { specialized complementary assets are held by incumbent firms, start-up }\end{array}$ \\
\hline
\end{tabular}




\begin{tabular}{|l|l|}
\hline Gans and Stern, & $\begin{array}{l}\text { firms generate more innovative rents by cooperation strategies. } \\
\text { - }\end{array}$ \\
When weak intellectual property for innovation exists alongside low \\
barriers to entry, competitive commercialization strategies are more \\
likely. \\
- Strategic management of innovation should focus less on whether a \\
particular technology is 'radical' in an engineering sense (i.e., \\
displacing existing technologies) and more on whether that technology \\
is 'radical' in an organizational or market sense. \\
If entrepreneurial innovation undermines existing incumbent assets, the \\
returns to cooperation are reduced in favor of competition.
\end{tabular}

\subsubsection{Christensen's work on innovation}

This section has been organized around two core theories: disruptive innovation; and capabilities (resources, processes and values (RPV).

The disruptive innovation theory builds on Bower and Christensen (1995), Christensen and Overdorf (2000) and Christensen, Johnson and Rigby (2002). The capabilities theory builds on the work of Christensen and Overdorf (2000). In addition, the book "Seeing what's next? using the theories of innovation to predict industry change" written by Christensen, Anthony and Roth (2004) describes these two core theories. 
Table 7: Perspectives of selected studies

\begin{tabular}{|c|c|c|c|}
\hline & Samples & Theory & Key Points \\
\hline $\begin{array}{l}\text { Bower and } \\
\text { Christensen } \\
\text { (1995) }\end{array}$ & $\begin{array}{l}\text { Hard drives; } \\
\text { Sony's portable } \\
\text { radios; personal } \\
\text { computers; } \\
\text { copy machines; } \\
\text { excavators; }\end{array}$ & $\begin{array}{l}\text { Resources, } \\
\text { processes } \\
\text { and values }\end{array}$ & $\begin{array}{l}\text { The technological changes that } \\
\text { damage established companies are } \\
\text { usually not radically new or difficult } \\
\text { from a technological point of view } \\
\text { - Established companies usually choose } \\
\text { to go up-market with sustaining } \\
\text { technologies and enter market } \\
\text { segments whose profit margins are } \\
\text { high } \\
\text { It's difficult to divert resources from } \\
\text { known customer needs in established } \\
\text { markets to markets and customers that } \\
\text { seem insignificant or do not exist } \\
\text { Once the entrant companies have } \\
\text { secured a foothold in the market and } \\
\text { improved the performance of their } \\
\text { products, they aim at the established } \\
\text { markets above them }\end{array}$ \\
\hline $\begin{array}{l}\text { Christensen } \\
\text { and } \\
\text { Overdorf } \\
(2000)\end{array}$ & $\begin{array}{l}\text { Toyota' low } \\
\text { end market; } \\
\text { Charles } \\
\text { Schwab's } \\
\text { discount } \\
\text { broker; }\end{array}$ & $\begin{array}{l}\text { Resources, } \\
\text { processes } \\
\text { and values }\end{array}$ & $\begin{array}{l}\text { Company's resources, processes and } \\
\text { values determine its actions in the } \\
\text { market } \\
\text { - Disruptive innovations create an } \\
\text { entirely new market through the } \\
\text { introduction of a new kind of product } \\
\text { or service that's actually worse }\end{array}$ \\
\hline
\end{tabular}




\begin{tabular}{|c|c|c|c|}
\hline $\begin{array}{l}\text { Christensen, } \\
\text { Johnson and } \\
\text { Rigby } \\
(2002)\end{array}$ & $\begin{array}{l}\text { Apple II, } \\
\text { Xerox; Apple's } \\
\text { Newton vs. } \\
\text { Palm's Pilot; } \\
\text { IBM's } \\
\text { ViaVoice } \\
\text { product; Xerox } \\
\text { vs. HP. }\end{array}$ & $\begin{array}{l}\text { Disruptive } \\
\text { innovation. }\end{array}$ & $\begin{array}{l}\text { Successful disruptive innovators } \\
\text { always target customers who welcome } \\
\text { simple products } \\
\text { - Once a viable disruptive growth } \\
\text { strategy has been defined, three } \\
\text { classes of factors - resources, } \\
\text { processes and values need to be } \\
\text { managed carefully }\end{array}$ \\
\hline
\end{tabular}

\subsubsection{Disruptive Innovation}

The disruptive innovation theoretical perspective examines situations in which new organizations use relatively simple, convenient, low-cost innovations, to successfully compete with incumbent companies. The disruptive innovation perspective holds that established companies have a high probability of beating new entrant attackers when the competition is anchored around sustaining innovations. Established companies, however, almost always lose to attackers armed with disruptive innovations (Christensen, Anthony and Roth, 2004).

Disruptive innovations create an entirely new market through the introduction of a new kind of product or service, one that's actually worse initially, as judged by the performance metrics that mainstream customers value (Christensen and Overdorf, 2000).

Sustaining innovations are what move companies along established improvement trajectories. They are improvements to existing products on dimensions historically valued by customers. Disruptive innovations introduce a new value proposition. They either create new markets or reshape existing markets. There are two types of disruptive innovations: new market and low- 
end. New market disruptive innovation occur when characteristics of existing products limit the number of potential consumers or force consumption to take place in inconvenient, centralized settings (Christensen et al., 2004). Low-end disruptive innovations occur when existing products and services are "too good" and hence overpriced relative to the value existing customers can use.

Figure 5 is reproduced from Christensen, Anthony and Roth's book titled "Seeing What's Next". It illustrates what is meant by sustaining innovations, new market disruption, and low-end disruptions. 
Figure 5: Disruptive innovation

\section{The Disruptive Innovation Theory}

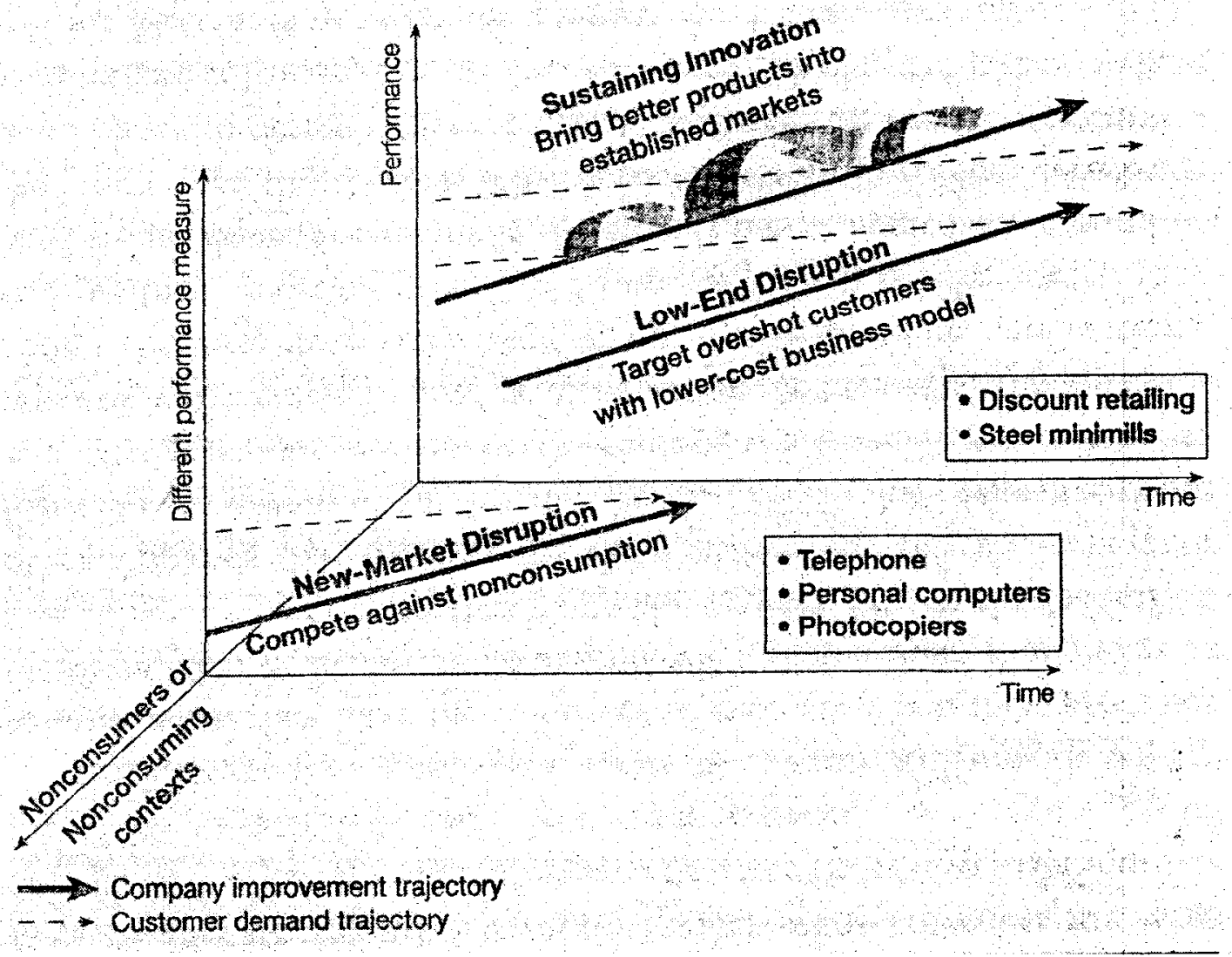

Source: (Christensen et al., 2004: xvi)

\section{Establishing a new market as a base for disruption}

It is much easier to target potential customers who are not buying at all than to steal customers from an entrenched competitor (Christensen, Johnson and Rigby, 2002). Instead of competing against a well established company, a new entrant can compete against non consumption. 


\section{Low cost as a base for disruption}

For a low end disruptive strategy to succeed, it must (i) target the least-demanding tiers of a market and (ii) the business model must enable the entrant to compete profitably while pricing at deep discounts (Christensen et al., 2002).

The only way a corporation can maintain its growth is by launching new growth business when the core units are strong (Christensen et al., 2002).

\subsubsection{Resources, Processes, and Values}

The resources, processes, and value (RPV) theoretical perspective focuses on company capabilities to explain why established companies find difficult to react to disruptive innovations. Table 8 is reproduced from Christensen et al. (2004). It illustrates a sample of resources, processes and values. Christensen define resources as things or assets that organizations can buy or sell, build or destroy, like people, equipment, technologies, and cash, and the less tangible ones like product designs, information, brands and relationships with suppliers, distributors, and customers. Processes are the established patterns of work by which companies transform inputs to outputs of greater worth. Values determine the criteria by which organizations allocate their resources. Christensen et al. (2004) define an organization's value as the standard by which employees set priorities that enable them to judge whether a customer is more important or less important, whether an idea for a new product is attractive or marginal, and so on. 
Table 8: Capabilities perspective

\begin{tabular}{|c|c|c|}
\hline Resources & Processes & Values \\
\hline $\begin{array}{l}\text { Things or assets that } \\
\text { organizations can buy or } \\
\text { sell,build or destroy. } \\
\text { Example: } \\
\text { - People } \\
\text { - Technology } \\
\text { - Products } \\
\text { - Equipment } \\
\text { - Information } \\
\text { - Cash } \\
\text { - Brand } \\
\text { - Distribution channels }\end{array}$ & $\begin{array}{l}\text { Established ways } \\
\text { companies turn resources } \\
\text { into products or services. } \\
\text { Examples: } \\
\text { - Hiring and training } \\
\text { - Product development } \\
\text { - Manufacturing } \\
\text { - Planning and } \\
\text { - } \quad \text { Market research } \\
\text { - Resource allocation }\end{array}$ & $\begin{array}{l}\text { The criteria by which } \\
\text { prioritization decisions } \\
\text { are made. Examples: } \\
\text { - Cost structure } \\
\text { - Income statement } \\
\text { - Customer demands } \\
\text { - Size of opportunity } \\
\text { - Ethics }\end{array}$ \\
\hline
\end{tabular}

Source: Christensen et al., 2004: xviii

The RPV theory argues that organizations successfully tackle opportunities when they have the resources to succeed, when their processes facilitate what needs to get done, and when their values allow them to give adequate priority to that particular opportunity in the face of all other demands that compete for the company's resources. Incumbent firms master sustaining innovations because their values prioritizing them, and their processes and resources are designed to tackle precisely those types of innovations. Incumbent firms fail in the face of disruptive innovations because their values will not prioritize disruptive innovations, and the firm's existing processes do not help them get done what they need to get done (Christensen et al., 2004). 
The factors that define an organization's capabilities and disabilities evolve over time - they start in resources; then move to visible, articulated processes and values, and migrate finally to culture. When the organization's capabilities reside primarily in its people, changing capabilities to address the new problems is relatively simple. But when the capabilities have come to reside in processes and values, and especially when they have become embedded in culture, change can be extraordinarily difficult (Christensen and Overdorf, 2000).

\subsubsection{Competitive Regimes}

As for the disruptive innovations, Adner (2002) pointed out that the demand-side factors that drive the emergence of competition remain largely unstudied in Christensen's explanations. So in his article, Adner developed a demand-based view of technology competition by formally modeling the demand environment in shaping competitive dynamics.

The structure of demand is characterized by two elements of the relationship between market segment preferences: preference overlap and preference symmetry. Preference overlap refers to the extent to which development activity that is valued in one segment is also valued in another segment. Preference symmetry refers to the symmetry of this overlap, the relative size of the functional 'shadows' that segments cast on each other.

Three distinct dynamics emerge during the course of the analysis. Under demand conditions of low preference overlap, the development dynamics lead to competitive isolation, a pure partitioning of the market between the technologies, such that each focuses exclusively on its own segment. As preference overlap increases, isolation breaks down and the development 
dynamics lead to the emergence of two distinct classes of competition. When segment preferences are symmetric we observe competitive convergence, in which each technology's development is directed at expanding its appeal not only in its own home market but in its rival's as well. When segment preferences are asymmetric we observe competitive disruption, in which one firm maintains dominance of its home market while displacing its rival from the rival's market (Adner, 2002).

\subsubsection{Commercialization Framework}

Existing commercialization frameworks (Teece, 1986; Gans and Stern, 2003) emphasize that to profit from innovation, a company must keep their knowledge secret or protect the innovation by legal means and must have access or control to key specialized complementary assets required to commercialize the innovation.

A firm has to examine three things in order to commercialize the innovation: (i) regimes of appropriability (including the nature of the technology and the efficacy of the legal protection mechanisms), (ii) dominant design, and (iii) access to complementary assets.

An appropriability regime involves the firm's ability to protect its innovation through legal mechanisms (i.e. IP protection) and the nature of the technology. Intellectual Property (IP) can be protected through patents, copyrights, and trade secrets. However, patents can be "invented around" and the cost of proving infringement is high. Trademarks are copyrighted words, symbols, and others used as the basis for brand identification. Strong brands give companies advantage over other imitations because of the brand's influence on the customers. Trade secrets 
provide protection when underlying technology or processes are kept hidden even when the product becomes available to the public.

The nature of technology can also contribute to the appropriability of an innovation. The product or the process involved might be difficult to imitate. The knowledge (tacit or codified) can also affect the degree of imitation. Codified knowledge can be easily transmitted and exposed. Tacit knowledge, however, is difficult to articulate and transfer. This requires those who posses the knowledge to demonstrate it to others.

When appropriability regime is weak, imitators can easily copy an innovation reducing the firm's ability to profit in the market. If appropriability regime is strong, the firm has a high probability of profiting from a market offer enabled by the innovation or by directly licensing the innovation to others.

However, most innovations require complementary assets for commercialization. Complementary assets refer to diverse competence and resources needed to bring the innovation to the market. The complementary assets are divided into generic, specialized, and co-specialized (Teece, 1986). Access to these assets is important for profitability. Who controls the assets determines who among the innovator, the imitator, and the owner of the complementary asset will profit from the innovation.

When the appropriability regime is weak, access to complementary assets becomes the more important. Innovators can build the required complementary assets themselves or they can 
contract it out. If the complementary asset required is generic, the innovator can contract for access. But when the complementary asset is specialized or co-specialized and the appropriability regime is weak, contracting becomes dangerous and it is better to build the complementary asset within the firm. Also, contracting may result in the owner of the complementary asset becoming a competitor especially when imitation of the innovation is easy. Unfortunately, when the innovator is a start-up and the imitator is the incumbent, the incumbent most often owns the complementary asset required for commercialization (Gans and Stern, 2003). Thus, the owner of the complementary asset may be the one to gain from the innovation (Rothaermel, 2001; Tripsas, 1997). Tripsas (1997) examined the typesetter industry and found that incumbents were able to survive the battles with new entrants because they owned the specialized complementary assets required for commercialization.

In some instances, substitutors may have competing innovation in the market. The company's commercialization decisions are influenced if there is already an established dominant design. When there is no dominant design for an innovation, it is said to be in the pre-paradigmatic stage. In this stage, there is no accepted and agreed upon "standards" which the design of a product can be based on. Companies fight to have their product design set as the dominant standard. When a promising design emerges and is able to meet most of the user's needs, then the paradigmatic stage has been reached. At this stage, competition shifts away from design towards price. Companies strives towards producing the product at a lower cost that their competitors. 
Companies also use access to complementary assets to be able to set dominant designs. Funk (2001) examined how suppliers of phones to DoCoMo established dominant designs over competitors in the mobile phone device market due to DoCoMo giving preferential access to information of the Japanese digital phone standard that DoCoMo controlled.

Table 9 highlights the overall pattern associated with each commercialization environment, as described by Gans and Stern (2003).

\section{Table 9: Commercialization strategy environments}

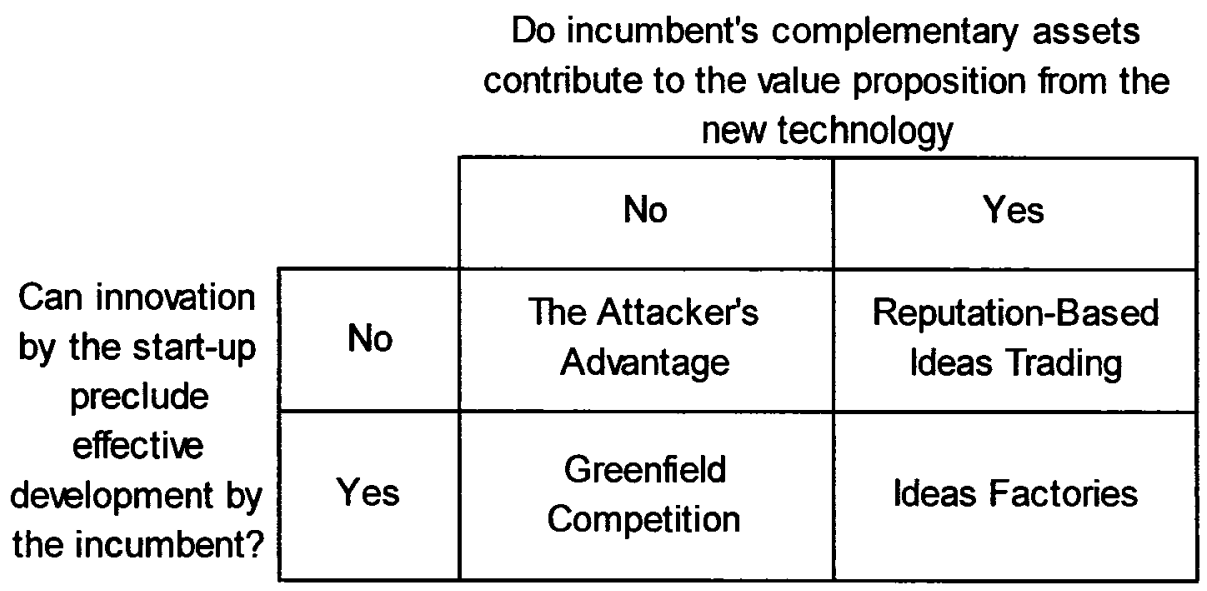

\subsection{Lessons Learned from the Literature Review}

This section provides the lessons learned from the literature review.

1. Lack of research on how open source companies use OSS to compete in a specific market (e.g., VoIP). The literature includes studies on how companies use OSS across different markest but studies that focus on how companies use OSS to compete in a specific market are lacking. 
2. OSS literature can be organized into: (i) motivations of contributors; (ii) innovation process; and (iii) competitive dynamics. Current literature deals with why developers contribute to OSS projects; how these projects develop the software; and how companies attempt to profit from OSS.

3. Motivations to participate in OSS projects are different between individuals and companies; most research has focused on the motivation of individuals. Companies participate for profit reasons. Participating in OSS projects involves investing resources and affects how they are able to generate revenue from OSS.

4. Disruptive innovation theoretical perspective examines situations in which new organizations use relatively simple, convenient, low-cost innovations, to successfully compete with incumbent companies. The disruptive innovation perspective holds that established companies have a high probability of beating new entrant attackers when the competition is anchored around sustaining innovations. Established companies, however, almost always lose to attackers armed with disruptive innovations.

5. The resources, processes, and value (RPV) theoretical perspective focuses on company capabilities to explain why established companies find difficult to react to disruptive innovations. Resources are things or assets that organizations can buy or sell, build or destroy. Processes are the established patterns of work by which companies transform inputs to outputs of greater worth. Values determine the criteria by which organizations allocate their resources. 
6. Competitive regimes can be of three types: Competitive isolation regime, competitive convergence regime, and competitive disruption regime. Demand-based view of technology competition is based on the relationship between market segment preferences: preference overlap and preference symmetry. There are three distinct competitive dynamics.

Competitive isolation represents a pure partitioning of the market between the technologies, in a competitive convergence regime, technologies evolve to compete head-on for the same customers, in a competitive disruption regime, one technology cedes dominance of its market to its rival technology.

7. Commercialization frameworks are based on ownership of IP and access to complementary assets owned by others. Who profits from an innovation depends on the innovator's ability to protect the IP of its innovation and its access to complementary assets. When an innovator can protect its IP, it has a high probability of profiting from the innovation. If the complementary asset required to commercialize the innovation is specialized, the owner of that specialized asset has a better chance of profiting from the innovation.

8. Companies have to integrate programs, services, and systems with their products to create attractive market offers. It is not enough for companies to develop products but they have to provide add-ons in order to meet or exceed customer expectations. 


\section{METHOD}

This chapter is organized into six sections. The first four sections describe the unit of analysis, study period, research method, and sample selection. The fifth section describes how the data were collected. Finally, the sixth section explains how the data was analyzed.

\subsection{Unit of analysis}

The unit of analysis is a software company that generates at its revenue through the sale of VoIP products and services that depend on the software of an open source project that was set up by the company or its founders.

\subsection{Study period}

The study period is from January 1995 to April 2006.

\subsection{Research method}

Table 10 provides the research steps undertaken to examine how companies use OSS in the VoIP market. For each step, the dominant activity undertaken and the reason for the step are identified. This research method builds on Zhen (2004). Zhen (2004) used Christensen's theoretical perspectives to examine the Chinese telecommunications equipment supplier industry.

Table 10: Research method

\begin{tabular}{|l|l|l|l|}
\hline No & \multicolumn{1}{|c|}{ Step } & \multicolumn{1}{c|}{ Activity } & Reason for the step \\
\hline 1 & Getting started & $\begin{array}{l}\text { Define a research question and } \\
\text { identify the reasons why it is relevant } \\
\text { Identify the contributions the }\end{array}$ & $\begin{array}{l}\text { Focuses efforts } \\
\text { Sets goals for } \\
\text { research completion }\end{array}$ \\
\hline
\end{tabular}




\begin{tabular}{|c|c|c|c|}
\hline & & research is expected to make & $\begin{array}{l}\text { Anchors review of } \\
\text { the literature }\end{array}$ \\
\hline 2 & Select sample & $\begin{array}{l}\text { Specify population of companies to } \\
\text { be examined. } \\
\text { Identify companies to examine based } \\
\text { on their data availability and } \\
\text { contribution to insights, not } \\
\text { randomness }\end{array}$ & $\begin{array}{l}\text { Focuses on available } \\
\text { companies } \\
\text { Provides flexibility to } \\
\text { decide what type of } \\
\text { companies and open } \\
\text { source projects can } \\
\text { be examined later }\end{array}$ \\
\hline 3 & $\begin{array}{l}\text { Select theoretical } \\
\text { perspectives }\end{array}$ & $\begin{array}{l}\text { Identify the theories that will provide } \\
\text { the lenses for the analysis }\end{array}$ & $\begin{array}{l}\text { Fixes the lenses for } \\
\text { the analysis }\end{array}$ \\
\hline 4 & $\begin{array}{l}\text { Define data } \\
\text { collection method }\end{array}$ & $\begin{array}{l}\text { Identify the method that will be used } \\
\text { to collect the data }\end{array}$ & $\begin{array}{l}\text { Strengthens } \\
\text { grounding }\end{array}$ \\
\hline 5 & $\begin{array}{l}\text { Collect data on } \\
\text { companies and } \\
\text { write cases }\end{array}$ & $\begin{array}{l}\text { Collect news releases and other } \\
\text { information publicly available on } \\
\text { companies that compete in the } \\
\text { telephony market } \\
\text { Write cases about the companies in } \\
\text { the sample }\end{array}$ & $\begin{array}{l}\text { Shortens the time } \\
\text { required for analyses } \\
\text { and reveals the } \\
\text { breadth and depth of } \\
\text { data } \\
\text { Gains familiarity } \\
\text { with the data }\end{array}$ \\
\hline 6 & $\begin{array}{l}\text { Collect data on } \\
\text { open source } \\
\text { projects }\end{array}$ & $\begin{array}{l}\text { For each company, identify the open } \\
\text { source projects with which it } \\
\text { interacts }\end{array}$ & $\begin{array}{l}\text { Gains familiarity } \\
\text { with the data }\end{array}$ \\
\hline 7 & $\begin{array}{l}\text { Analyze data and } \\
\text { develop timeline }\end{array}$ & $\begin{array}{l}\text { Develop a timeline that identifies } \\
\text { major events in the open source VoIP } \\
\text { market }\end{array}$ & $\begin{array}{l}\text { Gains familiarity } \\
\text { with the data } \\
\text { Organizes data based } \\
\text { on time }\end{array}$ \\
\hline 8 & $\begin{array}{l}\text { Analyze data and } \\
\text { generate insights }\end{array}$ & $\begin{array}{l}\text { For each company-open source } \\
\text { project, generate insights using } \\
\text { theoretical perspectives }\end{array}$ & $\begin{array}{l}\text { Examines data and } \\
\text { generate insights } \\
\text { through theoretical } \\
\text { lenses. }\end{array}$ \\
\hline
\end{tabular}




\subsubsection{Getting started}

At this stage the researcher defined the research question, its relevance and potential contribution.

\subsubsection{Select sample}

At this stage the researcher defined the criterion used to select the companies in the sample.

To identify the companies, the following five steps were undertaken:

1. Selected an open source project from the list of open source VoIP projects published at voipinfo.org ${ }^{4}$ portal, and Linux magazine ${ }^{5}$

2. Determined who were the founders of the OSS project

3. Determined if the founders' company generated rtevenue from market offers based on open source software. If yes, the company was included in the sample. If no, the company was not included in the sample.

\subsubsection{Select theoretical perspectives}

Four theoretical perspectives were identified to generate insights from the data. These theoretical perspectives include disruptive innovation theory (Bower and Christensen, 1995; Christensen and Overdorf, 2000; Christensen, Johnson and Rigby, 2002), demand based framework (Adner,

\footnotetext{
${ }^{4} \mathrm{http} / /$ www.voip-info.org/tiki-index.php?page=Open+Source+VOIP+Software

5 "VoIP Basics - Voice over IP basics explained" Linux-magazine 2004 (45), pp. 20-25. http://www.linux-magazine.com
} 
2001; 2002), commercialization strategy framework (Gans, Hsu and Stern, 2002; Gans and Stern, 2003), and Teece's commercialization framework (Teece, 1986;1988).

\subsubsection{Define data collection method}

Data was comprised of i. cases studies prepared for each company in the sample and its corresponsing open source project, ii. a timeline, and iii. appendices that captured relevant data about the companies and corresponding open source projects.

Data was collected from multiple sources accessible via the Web. The purpose of using multiple sources was to obtain complementary data to cover the issues in a complete way. The purpose of using multiple sources was not triangulation - the use of data from different sources to get at the same thing for verification.

Data was collected from the following sources:

- OSS development sites such as sourceforge.net and freshmeat.net

- open source communities websites and list servers

- vendor websites, brochures and documents

- press releases

- independent analyst reports

- media coverage

Table 11 describes the nature of the data collected and the source of the data. The data collected was organized into three broad categories. The first category included general information about 
the company and the corresponding open source project and the company's history, profile, and top management team. The second data category included information on the company's business models and offerings. The third data category included information on the company's motives for establishing or acquiring an open source project.

Table 11: Data collected and data source

\begin{tabular}{|l|l|}
\hline Data Collected & Data Source \\
\hline $\begin{array}{l}\text { About company and open } \\
\text { source project's general } \\
\text { information: company's } \\
\text { history, profile, TMT and open } \\
\text { source project's profile }\end{array}$ & $\begin{array}{l}\text { Company's website; } \\
\text { Open source community's website; } \\
\text { Forum messages from open source community; } \\
\text { Industry reports; } \\
\text { Media coverage }\end{array}$ \\
\hline $\begin{array}{l}\text { Company's business model } \\
\text { and offerings }\end{array}$ & $\begin{array}{l}\text { Company's website; } \\
\text { Forum messages from open source community }\end{array}$ \\
\hline $\begin{array}{l}\text { About company's motives for } \\
\text { project }\end{array}$ & $\begin{array}{l}\text { Company's website; } \\
\text { TMT's published interviews; } \\
\text { Industry reports; } \\
\text { Online articles from recognized IT magazines or } \\
\text { websites, } \\
\text { e.g., CNET news (news.com.com) } \\
\text { OpenEnterprise Trends.com (www.oetrends.com), } \\
\text { InfoWorld (www.infoworld.com), } \\
\text { eWEEK (www.eweek.com), } \\
\text { Linux Journal (www.linuxjournal.com), and } \\
\text { ComputerWold (www.computerworld.com); }\end{array}$ \\
\hline
\end{tabular}

\subsubsection{Collect data on companies and write cases}

Data on the nine companies in the sample was collected from publicly available sources. The raw data on the companies was arranged in the form of cases for each company. This simplified the data analysis. 


\subsubsection{Collect data on open source projects}

For each company in the sample, the open source projects that the company or its founders set up were identified.

\subsubsection{Analyze data and develop timeline}

From the data in the cases and the appendices, a timeline was developed. The purpose of the timeline was to identify major events in the open source VoIP market.

\subsubsection{Analyze data and generate insights}

Data was organized in the form of: i. cases about the companies in the sample, ii. tables and a iii. timeline for major events in the open source VoIP market.

Cases describing each company in the sample were prepared.

For each company, the following data were placed in tables: general information about the company, its products, its TMT and employees, and dates of the major events in the life of the company (Appendix B); its business models (Appendix C); and its OSS licenses (Appendix D).

The timeline organized data based on time/ gaining familiarity with the data and to organize data based on time. The timeline identifies the major events in the open source VoIP market. The events selected for inclusion in the timeline include:

- launching of OSS projects 
- setting up a company to generate revenue from OSS projects

- changes in the business models of companies

- launching of commercial products based on OSS.

Data was then examined to generate insights through theoretical lenses. Four theoretical perspectives were used to examine competition: disruptive innovation theory (Bower and Christensen, 1995; Christensen and Overdorf, 2000; Christensen, Johnson and Rigby, 2002), demand based framework (Adner, 2001; 2002), commercialization strategy framework (Gans, Hsu and Stern, 2002; Gans and Stern, 2003), and Teece's commercialization framework (Teece, 1986;1988). The insights were generated using the following steps:

1. For each company, data was examined first for its business model, products, licenses, and major events, as given in cases, tables and timeline

2. Each company's data was then passed through the lens of each of the four theoretical perspectives for explanation

3. Major findings of the examination in step 2 were noted down as insights 


\section{WRITE UP OF COMPANIES INCLUDED IN THE SAMPLE}

The sample used in this research is comprised of nine open source VoIP companies that generated revenues from open source VoIP applications in 2005.

For each company in the sample, Table 12 identifies the company's product market, the name of the open source project the company set up, and the URL of the company's website.

Table 12: Open source telephony companies included in the sample

\begin{tabular}{|c|l|l|l|l|}
\hline $\begin{array}{c}\text { No } \\
\cdot\end{array}$ & Company & $\begin{array}{l}\text { Company's } \\
\text { product market }\end{array}$ & $\begin{array}{l}\text { Open } \\
\text { source } \\
\text { project }\end{array}$ & Company's website \\
\hline 1 & Digium Inc. & VoIP/TDM PBX & Asterisk & http://www.digium.com \\
\hline 2 & Pingtel Corp. & VoIP PBX & sipX & http://www.pingtel.com \\
\hline 3 & Voicetronix & $\begin{array}{l}\text { TDM PBX and } \\
\text { Telephony } \\
\text { application } \\
\text { server }\end{array}$ & $\begin{array}{l}\text { OpenPBX } \\
\text { and CT } \\
\text { server }\end{array}$ & http://www.voicetronix.com.au \\
\hline 4 & Null Team & $\begin{array}{l}\text { Softswitch or } \\
\text { Call Agent }\end{array}$ & YATE & http://www.null.ro \\
\hline 5 & $\begin{array}{l}\text { Tycho } \\
\text { Softworks }\end{array}$ & IVR Platform & $\begin{array}{l}\text { GNU } \\
\text { Bayonne 2 }\end{array}$ & http://www.tychosoft.com/ \\
\hline 6 & iptel.org & SIP Server & $\begin{array}{l}\text { SIP Express } \\
\text { Router } \\
\text { (SER) }\end{array}$ & http://www.iptel.org/ \\
\hline 7 & $\begin{array}{l}\text { Vovida } \\
\text { Networks }\end{array}$ & $\begin{array}{l}\text { Telephony } \\
\text { application } \\
\text { server }\end{array}$ & VOCAL & Acquired by Cisco in 2000 \\
\hline 8 & $\begin{array}{l}\text { Equivalence } \\
\text { Pty Ltd. }\end{array}$ & $\begin{array}{l}\text { Open source } \\
\text { H.323 stack }\end{array}$ & OpenH323 & $\begin{array}{l}\text { Acquired by } \\
\text { Technologies Inc. USA in 2000 }\end{array}$ \\
\hline 9 & Antisip & $\begin{array}{l}\text { Open source SIP } \\
\text { stack }\end{array}$ & oSIP & http://www.antisip.com/ \\
\hline
\end{tabular}


Appendix A provides a comparison of software licenses. Appendix B provides general information about the companies, their products, their TMT and employees, and dates of the major events in the life of these companies. Appendix $\mathrm{C}$ provides information about the business models of the nine open source VoIP companies. Appendix D summarizes information about the different software licenses of the open source VoIP projects.

Table 13 provides a profile of the companies in the sample. The profile was developed using the data included in Appendix B. The range of the age of the nine open source companies in the sample is between one and eleven years. Four companies ( $44 \%$ of sample) were founded before 2000. Four of the nine open source companies (44\%) were founded in the USA, two in Australia, one in Germany, one in France and one in Romania. Seven of the nine companies (78\%) were founded to be open source companies. Two companies first operated as traditional proprietary software companies and then transformed into open source companies. These two companies released their proprietary software to the open source project that they set up. No company in the sample has obtained VC funding.

Table 13: Sample profile

\begin{tabular}{|l|c|c|}
\hline Group & $\begin{array}{c}\text { Number of } \\
\text { companies }\end{array}$ & $\begin{array}{c}\text { Percentage of } \\
\text { companies in sample }\end{array}$ \\
\hline Companies founded before 2000 & 4 & $44 \%$ \\
\hline Companies founded in 2000 and after & 5 & $56 \%$ \\
\hline Companies founded in the United States & 4 & $44 \%$ \\
\hline Companies founded in Europe & 3 & $33 \%$ \\
\hline Companies founded in Australia & 2 & $22 \%$ \\
\hline
\end{tabular}




\begin{tabular}{|l|c|c|}
\hline Companies founded to work with OSS & 7 & $78 \%$ \\
\hline Companies not founded to work with OSS & 2 & $22 \%$ \\
\hline $\begin{array}{l}\text { Companies that received VC funding to go } \\
\text { open source }\end{array}$ & 0 & $0 \%$ \\
\hline
\end{tabular}

\subsection{Digium}

Mark Spenser, who is the creator and primary developer of Asterisk, the industry's first open source VoIP PBX, established Digium Inc., formerly known as 'Linux Support Services'. Digium released the first version of Asterisk in December 1999 under the GNU GPL license. Digium released the OSS through the open source community 'Asterisk' it had established. Digium's initial business model was anchored around selling complementary hardware and services for the hardware.

Initially, Asterisk was of limited performance, and it was not of production grade. With time the performance of the Asterisk telephony application improved to the level that it could be deployed reliably in enterprises. In May 2005, Digium launched the Asterisk business edition with more traditional software licensing and warranties. The professional-grade version of Asterisk was tailored to small- and medium-sized business applications.

Digium claims that the Asterisk business edition is based entirely on the same OSS available from the Asterisk open source community, and that the value created is due to packaging, i.e., the aggregation, integration, and optimization of the freely available software components. The business edition is provided in binaries only and its use is granted for an annual fee. The Asterisk business edition comes with a full year of limited software support and free upgrades. Support 
for configuring or debugging specific end-user applications is not included, but can be purchased separately at a discounted rate. An optional annual maintenance plan extends the support period and allows free upgrades upon request.

The business edition protects the company against piracy. First, it is in binary to hide the internal structure. Second, a registration program creates a signed key that allows business edition to run solely on a single system. Moreover, distributing a system that includes a company's trademarks would violate the intellectual property rights (IPR) laws. Being the copyright owner of the software, Digium can offer its business edition under any license and can mix it with any type of software. The reason that the business edition does not carry the features of the GPL software like free distribution by users is that it contains Digium trademarks in the software.

A third party which wants to generate revenue from Asterisk open source VoIP PBX can not use the name 'Asterisk' except only after taking permission from the trademark holder, Digium. This third party can modify the software, and is not required to disclose its source except to its customers. But then the consumers can distribute this source as they are permitted to do so under the GPL license.

Today Digium generates revenue from multiple sources including licensing of Asterisk business edition, selling interface cards for Asterisk, licensing Asterisk code outside of the GPL for use in proprietary applications and selling services such as consulting and support. All these different revenue generation schemes can be summarized as dual licensing (GPL and commercial), and service provisioning. Dual licensing is made possible by accepting only those contributions in 
Asterisk which are disclaimed by its original authors. Digium is concentrating on three areas for growth and customizing its Asterisk product accordingly: Business solutions, Internet telephony service providers (ITSP)/carriers, including hosted VoIP providers, and call/contact centers.

Digium is also trying to assure its customers that they will not be locked in or lose their investment in case Digium goes out of business in the future or is acquired by some other company. For this reason, in 2005 Digium started supporting Intel Corp.'s modular platforms for communicatons systems (Netstructure and Dialogic products) in its Asterisk business edition. This provides Digium's business edition customers the choice to use either Digium hardware for TDM interconnection or Intel's hardware platform. The support for Intel's platforms will also enable Digium to scale its business edition for large enterprises with the addition of more options and features.

The Asterisk open source community was forked in 2005 , and a new open source community 'OpenPBX.org' was established. If developers part to the OpenPBX.org community and do not disclaim their work there for Digium to use it in its proprietary solutions, then it is not to the advantage of Digium. Digium will also lose control over its code. It will become more difficult for Digium to change its current open source license of GPL to something different in the presence of another open source community, and thus may have less potential for any possible acquisition in the future. However, the data shows that the 'OpenPBX.org' community is not doing well as compared to Asterisk, as the latter has the advantage of strong branding. 


\subsection{Pingtel}

Pingtel was founded in 1999 . It received \$25 million venture capital. Initially, Pingtel sold softphones and in April 2003 the company launched VoIP PBX 'SIPxchange'. In February 2004, upon recommendation of its venture capitalists, Pingtel established Sipfoundry.org, an open source community, and released its VoIP PBX software to the community under the GNU LGPL license. The objective of releasing the code was to disrupt rivals like Avaya, Cisco and Nortel. Pingtel also sold the IP hardphone portion of its business and became fully software oriented.

Today Pingtel generates revenue by packaging the software from the SIPfoundry.org and selling it under a commercial license with support options to SMEs. Pingtel provides consulting services also.

SIPfoundry releases the software with the name "sipX", while Pingtel uses the trademark "SIPxchange" for its packaged product. SIPxchange, like Asterisk business edition, is tested for reliability to work in enterprises, and is certified for work with other complementary equipment. The main difference between Pingtel and Digium is that Pingtel is software oriented, while Digium generates revenue from both hardware and software. Digium released Asterisk under the GPL license while Pingtel uses the LGPL license.

\subsection{Voicetronix}

Voicetronix was founded as a privately owned Australian company in 1995. Today the company is a leading supplier of open source computer telephony hardware. 
Voicetronix, operated from Adelaide and Sydney in Australia, is the primary developer of the open source PBX application 'OpenPBX'. OpenPBX was launched in May 2003. It does not support voice over Internet Protocol telephony (VoIP) at present and is a pure time divisions multiplex (TDM) PBX. Voicetronix is working to add VoIP functionality to OpenPBX. The purpose of launching OpenPBX was to sell hardware for it, and also to increase the demand for its hardware needed for another software - CT server, an open source telephony applicaton server.

There are two different open source projects with OpenPBX in their names. One called OpenPBX which was created by Voicetronix and the second one called OpenPBX.org which is the Asterisk fork. Besides OpenPBX, Voicetronix is also the developer of the 'CT server' application server.

Voicetronix generates revenue by selling the hardware required for open source PBXs, OpenPBX and Asterisk, and the application servers, CT server and Bayonne.

\subsection{Null Team}

Null Team is a software company started in 2004 in Romania. Its primary product is YATE (Yet Another Telephony Engine) softswitch, usable in a variety of customized applications. YATE's license is GPL with an exception for linking with OpenH323 and PWlib (licensed under MPL). Null team generates revenue by consulting services, and sell solutions based on YATE to call centers, telephony carriers, enterprises and the soho market. 
YATE supports the following VoIP protocols: H323, SIP, IAX1, IAX2, and RTP. For the plain old telephony systems (PSTN) it supports ISDN BRI and PRI. YATE is a next-generation telephony engine. Its attractiveness lies in its ability to be easily extended. Voice, video, data and instant messaging can all be unified under YATE's flexible routing engine, maximizing communications efficiency and minimizing infrastructure costs for businesses. YATE can be a VoIP server, VoIP client, or VoIP to PSTN gateway.

\subsection{Tycho Softworks}

David Sugar established Tycho Softworks in NJ, USA, in 2005. The company creates value from the GNU Bayonne telephony application server. David Sugar is the primary author and active maintainer of the GPLed Bayonne as well as a number of other projects.

GNU Bayonne, open source telephony application server, project was launched by Free Software Foundation Inc. Boston, MA, USA, the main contributors are David Sugar and Richard Bodo. The purpose was to establish 'free software' as the primary means to advance telecommunications services that respects software freedom.

Tycho Softworks offers commercial support and professional services to GNU Bayonne users worldwide. It designs and develops customized telephony applications (i.e., IVR applications) for clients.

GNU Bayonne started in mid-2000 and has been in wide use in e-government, commercial organizations and carriers since 2001. GNU Bayonne provides voice response application 
services that can integrate freely with other services. The 2002 Singapore Linux conference awarded "Best new enterprise infrastructure application of the year" to GNU Bayonne. Future plans for Bayonne include adding IP voice support.

\section{6 iptel.org}

iptel.org, an offshoot of the German national research company Fraunhofer Fokus, was established by Jiri Kuthan in 2002. It is a SIP know-how and deployment company. It created the open source SIP server called SIP Express Router (SER). iptel.org provides consultancy to both operators and vendors operating in the SIP domain.

SIP Express can be set up to serve a variety of purposes: Registrar, stateless and/or stateful Proxy Server, Redirect Server, and stateless/stateful User Agent Server. In addition to voice call signaling, SER includes support for SMS, presence, SIP-based instant messaging and a jabber gateway among other applications. SER is a fully-fledged SIP infrastructure of carrier grade quality. With its modular architecture, scalable design and rich set of features it is ideally suited to satisfy the needs of large carriers as well as small enterprises.

\subsection{Vovida Networks}

Luan Dang and Alan Knitowski started Vovida Networks, a packet communications networking software company, in San Jose, USA, in 1999. Its primary product was VOCAL (Vovida Open Communication Application Library) which is open source and available from a community web site called vovida.org along with the SIP, MGCP, RTP, and H.323 Annex F protocol stacks. The purpose was to (1) to level the playing field allowing everyone who wanted to participate in the 
VoIP development to do so without a huge $\$ \$$ investment, (2) to promote the adoption of VoIP standards and Voice over IP, (3) it was a fabulous marketing ploy to gain recognition (no one else was open sourcing as many protocols and applications dedicated to VoIP from one location), and (4) it created a certain amount of market disruption.

The Vovida Open Communication Application Library (VOCAL) is an open source project targeted at facilitating the adoption of VoIP in the marketplace. VOCAL provides the development community with the software and tools required to build new VoIP features, applications and services.

VOCAL is governed by Vovida software license version 1.0 which is a BSD-style license that enables developers to download the code without paying any royalties or fees, make changes without having to send the changes back to the Vovida's code repository, and use the code within new proprietary applications. VOCAL uses Session Initiation Protocol (SIP) to set up and tear down phone calls.

Vovida Networks generated revenue through consulting and support services for its VOCAL library and its different protocol stacks, e.g., it was selling a maintenance agreement for SIP stack for $\$ 5000 /$ year.

Vovida Networks was acquired shortly after its transition from a development company to an operating company. Vovida networks along the rights to the vovida.org domain name for VOCAL and VoIP protocol stacks project was acquired by Cisco Systems in September 2000, 
for $\$ 369$ million in Cisco common stock. Cisco continued to pay the Vovida Networks' engineers to develop the open source VoIP software. The reason behind Cisco's investment was to accelerate the development and adoption of new VoIP applications and to help make the Internet more useful, and thus to increase the demand for Cisco networking equipment such as routers and gateways.

\subsection{Equivalence}

Robert Jongbloed and Craig Southeren established Equivalence Pty Ltd in Australia in 1996. The company developed Internet protocol and interface software for both the retail and OEM markets. Its main product, OpenH323, was released in 1998 as open source software using the MPL license and was made available at the web site openh323.org. The purpose was to create an open source implementation of $\mathrm{H} .323$ protocol suite and to provide commercial support and services on top of it. OpenH323, an open source implementation of the ITU H.323 protocol, provides interoperability between users, gateways and gatekeepers.

Equivalence generated revenue from OSS through consulting and support services for OpenH323 protocol stack.

In early 2000, Robert and Craig sold Equivalence Pty Ltd and the right to the openh323.org domain name to a US company called Quicknet Technologies Inc. Quicknet is the leading provider of Internet telephony products. The acquisition expanded Quicknet's ability to supply custom interfaces for OpenH323 with their hardware and software and to provide commercial support for software and product developers seeking the most effective use of OpenH323 in their 
projects. Quicknet leveraged the H.323 technology to further develop its solutions, and integrated the technology into its software product, Internet SwitchBoard. Quicknet retained the open source nature of the OpenH323 project.

\subsection{Antisip}

Antisip was established by Aymeric Moizard in 2005 in Lyon, France, to create value from GNU open-source Session Initiation Protocol (oSIP) and other open source SIP products. Aymeric Moizard is the primary author of the LGPLed oSIP stack.

The GNU oSIP stack is an open source implementation of the IETF SIP protocol - a lightweight replacement of H323. oSIP stack project was launched in September 2000 by Free Software Foundation Inc. Boston, MA, USA,. It was written in C, and is very small and flexible. This allows using oSIP in embedded devices and creates the foundation of mobile internet phones based on Free Software. The purpose was to establish 'free software' as the primary means to advance telecommunications services that respects software freedom.

Antisip generates revenue by providing its experience and knowledge on the SIP protocol for building voice over IP projects for clients. It provides consulting and support services for oSIP stack and other free/open source SIP products. It provides commercial licenses for oSIP and other open source SIP products for use in proprietary applications outside the LGPL. 


\section{RESULTS}

This chapter is organized into three sections. The first section provides the timeline for the major events in the open source VoIP market. The second section uses the disruptive and capabilities perspectives to compare the open source and proprietary VoIP companies. The third section provides the insights generated from using four theoretical perspectives to examine the data.

\subsection{Timeline for the major events in the open source VoIP market}

An event driven timeline was developed that describes major events in the open source VoIP market. The events selected for the timeline include launching of the open source project, setting up a company to generate revenue from open source projects, changes in the business models of those companies, and launching of the commercial products based on OSS. Timelines are important in understanding the chronological sequence of events.

Table 14: Timeline for the major events in the open source VoIP market

1998

OpenH323, open souce H.323 Library, project was launched by Equivalence Pty Ltd. in Australia. The purpose was to create an open source implementation of $\mathrm{H} .323$ protocol suite and to provide commercial support and services on top of it. 
1999

Asterisk, open source VoIP PBX, project was launched by Linux Support Services Inc. (later became Digium) in Huntsville, Alabama, USA in December. The purpose was to generate revenue by selling hardware and support services for Asterisk

Vovida Open Communication Application Library (VOCAL) which is open source telephony application server, and open source SIP, RTP, MGCP and H.323 Annex F VoIP protocol stacks were launched by Vovida Networks Inc. in San Jose, CA, USA. The purpose was to (1) to level the playing field allowing everyone who wanted to participate in the VoIP development to do so without a huge $\$ \$$ investment, (2) to promote the adoption of VoIP standards and Voice over IP, (3) it was a fabulous marketing ploy to gain recognition (no one else was open sourcing as many protocols and applications dedicated to VoIP from one location), and (4) it created a certain amount of market disruption. Vovida Networks was acquired shortly after its transition from a development company to an operating company.

2000

GNU Bayonne, open source telephony application server, project was launched by Free Software Foundation Inc. Boston, MA, USA, the main contributors are David Sugar and Richard Bodo. The purpose was to establish 'free software' as the primary means to advance telecommunications services that respects software freedom.

GNU open-source Session Initiation Protocol (oSIP), open source implementation of SIP protocol suite, project was launched by Free Software Foundation Inc. Boston, MA, USA, the primary author is Aymeric Moizard. The purpose was to establish 'free software' as the primary means to advance telecommunications services that respects software freedom.

Vovida networks along the rights to the vovida.org domain name for VOCAL and VoIP protocol stacks project was acquired by Cisco in November for $\$ 369$ million (US) in Cisco common stock. The purpose was to accelerate the development and adoption of new VoIP applications and to help make the Internet more useful, and thus to increase the demand for Cisco networking equipment.

Equivalence Pty Ltd. along with the rights to the openh323.org domain name was acquired by Quicknet Technologies Inc. USA. The purpose of the acquisition was to expand Quicknet's ability to supply custom interfaces for OpenH323 with their hardware and software and to provide commercial support for software and product developers seeking the most effective use of OpenH323 in their projects. 
2002

SIP Express Router (SER), an open source SIP proxy, redirect, and registrar server, project was launched by 'iptel.org'- an offshoot of German national research company Fraunhofer Fokus. The purpose was to create an open source SIP-based VoIP platform and to create value from it.

CT Server, an open source application server, project was launched by a company 'Voicetronix' in Adelaide, Australia. The purpose was to sell hardware needed for the software

2003

OpenPBX, open source PBX, project was launched by a company 'Voicetronix' in May in Adelaide, Australia. The purpose was to sell hardware for it, and also to increase the demand for its hardware needed for another software - CT server, an open source telephony applicaton server.

2004

Pingtel went open source. Pingtel gave the complete code of the SIPxchange VoIP PBX to the newly established SIPfoundry open source community, and came up with generating revenue through business edition and services.

Yet Another Telephony Engine (YATE), open source softswitch, project was launched by a company 'Null Team' in Romania. The purpose was to create value from YATE by selling solutions.

2005

Launch of Asterisk business edition by Digium in May that was a significant shift in the business model of Digium. Asterisk made a deal with Intel for hardware thus providing an alternative to its Asterisk business edition customers and to show the non-locking features of its product. Asterisk fork 'OpenPBX.org' was established

A company 'Tycho Softworks' was established by David Sugar in NJ, USA, to create value from GNU Bayonne telephony application server. It offers services to GNU Bayonne users worldwide.

A company 'Antisip' was established by Aymeric Moizard, the primary author of oSIP, in France in January to create value from oSIP open source SIP library. It provides services around oSIP and other free/open source software. It offers support, training, bug fixes, help and software. 


\subsection{Comparing open source and proprietary VoIP PBX companies using disruptive technology and capabilities perspective}

This section is organized into three subsections. Subsection 5.2.1 identifies the competitive regimes observed from 1998 to February 2006. Subsection 5.2.2 compares open source and proprietary VoIP companies during the competitive isolation regime. Subsection 5.2.3 compares open source and proprietary VoIP companies during the competitive convergence regime.

Figure 1 on page 14 shows that the VoIP network infrastructure consists of various segments and components, and an OSS project targets a specific segment of this infrastructure and not the entire infrastructure. The comparison between open source and proprietary VoIP companies will be made only for the enterprise VoIP network segment using disruptive technology and capabilities perspective, and will not be compared for the carrier VoIP networks segment. Open source VoIP did not target the carrier networks as that VoIP segment is too complex and demanding, involving interoperability between many continuously evolving components and technologies. This comparison applies to two open source VoIP PBX companies, Digium and Pingtel. 
The second and third subsections start with a table that compares the salient characteristics of open source and proprietary VoIP PBX companies for each competitive regime based on the seven constructs emphasized by the technology disruption and capabilities perspectives. For disruptive technology perspective, the discussion is anchored around three constructs: (i) the market, (ii) the product that drives technological advances, and (iii) the factors that drive demand. For capabilities perspective, the discussion is anchored around four constructs: (i) technology, (ii) brand, (iii) product development, and (iv) priorities. The first two components focus on companies' resources, component (iii) focuses on companies' processes, and component (iv) focuses on companies' values.

\subsubsection{Competitive regimes for open source VoIP PBX identified}

The existence of two competitive regimes for open source VoIP PBX was observed: a competitive isolation regime and a competitive convergence regime. Clear evidence of the existence of a competitive disruption regime was not observed. The competitive regimes identified were used to organize the comparison between open source and proprietary VoIP PBX companies.

For the purpose of this research, the competitive isolation regime started with the foundation of the first open source VoIP PBX company, Digium, in 1999 and ended in 2004 when Pingtel introduced an open source communications solution for small businesses.

During this regime, technologies held by open source and proprietary VoIP PBX suppliers did not interact in the course of their evolution. Open source VoIP PBX companies actively involved 
in the open source projects to make them successful, and generate revenues by selling hardware and limited support services for environments which were not mission critical. On the other hand, proprietary VoIP PBX companies addressesd the needs of the enterprises and to generate revenue by giving solutions for migration of the old business communications systems to VoIPbased systems.

The competitive convergence regime started in 2004 and continues today. In a competitive convergence regime, technologies evolve to compete head-on for the same customers. The open source VoIP PBX companies' introduction of communications solutions for businesses marked the start of the competitive convergence regime. Open source and proprietary suppliers competed head to head for the SMEs market. By the end of 2005, two open source VoIP PBX companies, Digium and Pingtel, were competing in the VoIP market. There are also several other companies who are trying to upgrade their present open souce VoIP products to VoIP PBX by adding, for example, the features required for PBXs. Such companies include Voicetronix, Null Team and Tycho Softworks.

There is no evidence that a competitive disruption regime has started in the VoIP PBX market. In a competitive disruption regime, one technology cedes dominance of its market to its rival technology.

\subsubsection{Competitive isolation: 1998 to 2004}

Table 15 uses the constructs of two theoretical perspectives to compare the open source and proprietary VoIP PBX companies from 1998 to 2004. 
Table 15: The 1998-2004 competitive isolation regime

\begin{tabular}{|c|c|c|c|}
\hline \multirow[t]{2}{*}{$\begin{array}{l}\text { Theoretical } \\
\text { perspective }\end{array}$} & \multirow[t]{2}{*}{$\begin{array}{l}\text { Construct } \\
\text { emphasized }\end{array}$} & $\begin{array}{l}\text { Open source VoIP PBX } \\
\text { companies }\end{array}$ & $\begin{array}{l}\text { Proprietary VoIP PBX } \\
\text { companies }\end{array}$ \\
\hline & & Digium & Cisco, Avaya, Nortel \\
\hline \multirow[t]{3}{*}{$\begin{array}{l}\text { Disruptive } \\
\text { technology }\end{array}$} & Market & $\begin{array}{l}\text { Provided hardware and } \\
\text { limited support services for } \\
\text { open source software. } \\
\text { Targeted individuals }\end{array}$ & $\begin{array}{l}\text { Provided proprietary } \\
\text { software and hardware for } \\
\text { businesses }\end{array}$ \\
\hline & $\begin{array}{l}\text { Products driving } \\
\text { technological } \\
\text { advances }\end{array}$ & $\begin{array}{l}\text { Low capacity VoIP } \\
\text { products designed to } \\
\text { satisfy the demands of } \\
\text { individuals }\end{array}$ & $\begin{array}{l}\text { Large capacity VoIP } \\
\text { products designed to } \\
\text { satisfy the communication } \\
\text { requirements of businesses } \\
\text { of all sizes }\end{array}$ \\
\hline & $\begin{array}{l}\text { Factors driving } \\
\text { demand }\end{array}$ & $\begin{array}{l}\text { Customers required cheap, } \\
\text { easy to operate VoIP } \\
\text { products with basic } \\
\text { functions that did not } \\
\text { require educated } \\
\text { professionals to operate } \\
\text { them }\end{array}$ & $\begin{array}{l}\text { Customers required high } \\
\text { capacity VoIP products } \\
\text { with stable performance }\end{array}$ \\
\hline \multirow[t]{4}{*}{ Capabilities } & Technology & $\begin{array}{l}\text { Developed through open } \\
\text { source projects }\end{array}$ & $\begin{array}{l}\text { Developed within the } \\
\text { company }\end{array}$ \\
\hline & Brand & Not well known & Well known brands \\
\hline & $\begin{array}{l}\text { Product } \\
\text { development }\end{array}$ & $\begin{array}{l}\text { R\&D and product } \\
\text { development in the open } \\
\text { source projects } \\
\text { Designed and developed } \\
\text { products to meet the needs } \\
\text { of individuals }\end{array}$ & $\begin{array}{l}\text { R\&D and product } \\
\text { development within the } \\
\text { companies }\end{array}$ \\
\hline & Prionities & $\begin{array}{l}\text { Active involvement in the } \\
\text { open source projects to } \\
\text { achieve company's } \\
\text { objectives }\end{array}$ & $\begin{array}{l}\text { High profit margins from } \\
\text { sales of VoIP products }\end{array}$ \\
\hline
\end{tabular}




\subsubsection{Competitive convergence: 2004 to February 2006}

Table 16 compares the open source and proprietary VoIP PBX companies from 2004 to February 2006 using the constructs of disruptive technology and capabilities perspectives.

Table 16: The 2004-February 2006 competitive convergence regime

\begin{tabular}{|c|c|c|c|}
\hline \multirow[t]{2}{*}{$\begin{array}{l}\text { Theoretical } \\
\text { perspective }\end{array}$} & \multirow[t]{2}{*}{$\begin{array}{l}\text { Construct } \\
\text { emphasized }\end{array}$} & $\begin{array}{l}\text { Open source VoIP PBX } \\
\text { comapanies }\end{array}$ & $\begin{array}{l}\text { Proprietary VoIP PBX } \\
\text { companies }\end{array}$ \\
\hline & & Digium, Pingtel & Cisco, Avaya, Nortel \\
\hline \multirow[t]{3}{*}{$\begin{array}{l}\text { Disruptive } \\
\text { technology }\end{array}$} & Market & $\begin{array}{l}\text { Providing products and } \\
\text { services to consumers } \\
\text { Cheaper solutions for } \\
\text { small to medium } \\
\text { entreprises }\end{array}$ & $\begin{array}{l}\text { Provides products and } \\
\text { services to businesses of } \\
\text { all sizes }\end{array}$ \\
\hline & $\begin{array}{l}\text { Products driving } \\
\text { technological } \\
\text { advances }\end{array}$ & $\begin{array}{l}\text { Tested and reliable } \\
\text { products for SMEs }\end{array}$ & $\begin{array}{l}\text { Tested and reliable } \\
\text { products for businesses } \\
\text { of all sizes }\end{array}$ \\
\hline & $\begin{array}{l}\text { Factors driving } \\
\text { demand }\end{array}$ & $\begin{array}{l}\text { Cheaper product; } \\
\text { combination with Wi Fi } \\
\text { Solutions for specific } \\
\text { needs, maintenance and } \\
\text { support services }\end{array}$ & $\begin{array}{l}\text { Brands, large capacity } \\
\text { Solutions for specific } \\
\text { needs, extended support } \\
\text { services, } \\
\text { broad product portfolio }\end{array}$ \\
\hline \multirow[t]{2}{*}{ Capabilities } & Technology & $\begin{array}{l}\text { Reliable VoIP produts } \\
\text { for small to medium } \\
\text { businesses }\end{array}$ & $\begin{array}{l}\text { High reliable VoIP } \\
\text { produts for business of } \\
\text { all sizes }\end{array}$ \\
\hline & Brand & $\begin{array}{l}\text { Open source VoIP } \\
\text { companies are becoming } \\
\text { well known in the market }\end{array}$ & Well-known brands \\
\hline
\end{tabular}




\begin{tabular}{|l|l|l|l|}
\hline Product development & $\begin{array}{l}\text { R\&D and product } \\
\text { development in the open } \\
\text { source projects } \\
\text { Value is added by the } \\
\text { companies by packaging } \\
\text { of the software }\end{array}$ & $\begin{array}{l}\text { R\&D and product } \\
\text { development within the } \\
\text { companies }\end{array}$ \\
\cline { 2 - 4 } & Priorities & $\begin{array}{l}\text { Reduce functionality } \\
\text { gaps with proprietary } \\
\text { VoIP companies }\end{array}$ & $\begin{array}{l}\text { Increase global market } \\
\text { share in VoIP products } \\
\text { Increase product } \\
\text { reliability and capacity } \\
\text { Displace proprietary } \\
\text { VoIP companies in } \\
\text { SMEs market and grow } \\
\text { market share }\end{array}$ \\
\hline
\end{tabular}

\subsection{Insights}

Data from the write ups of nine open source VoIP companies and the appendices A-D was examined to generate insights through theoretical lenses. Four theoretical perspectives were used to examine competition in the VoIP market: disruptive innovation theory (Bower and Christensen, 1995; Christensen and Overdorf, 2000; Christensen, Johnson and Rigby, 2002), demand based framework (Adner, 2001; 2002), commercialization strategy framework (Gans, Hsu and Stern, 2002; Gans and Stern, 2003), and commercialization framework (Teece, 1986; 1988). The following insights were generated: 


\subsubsection{Using the lenses of disruptive innovation theory and demand based framework}

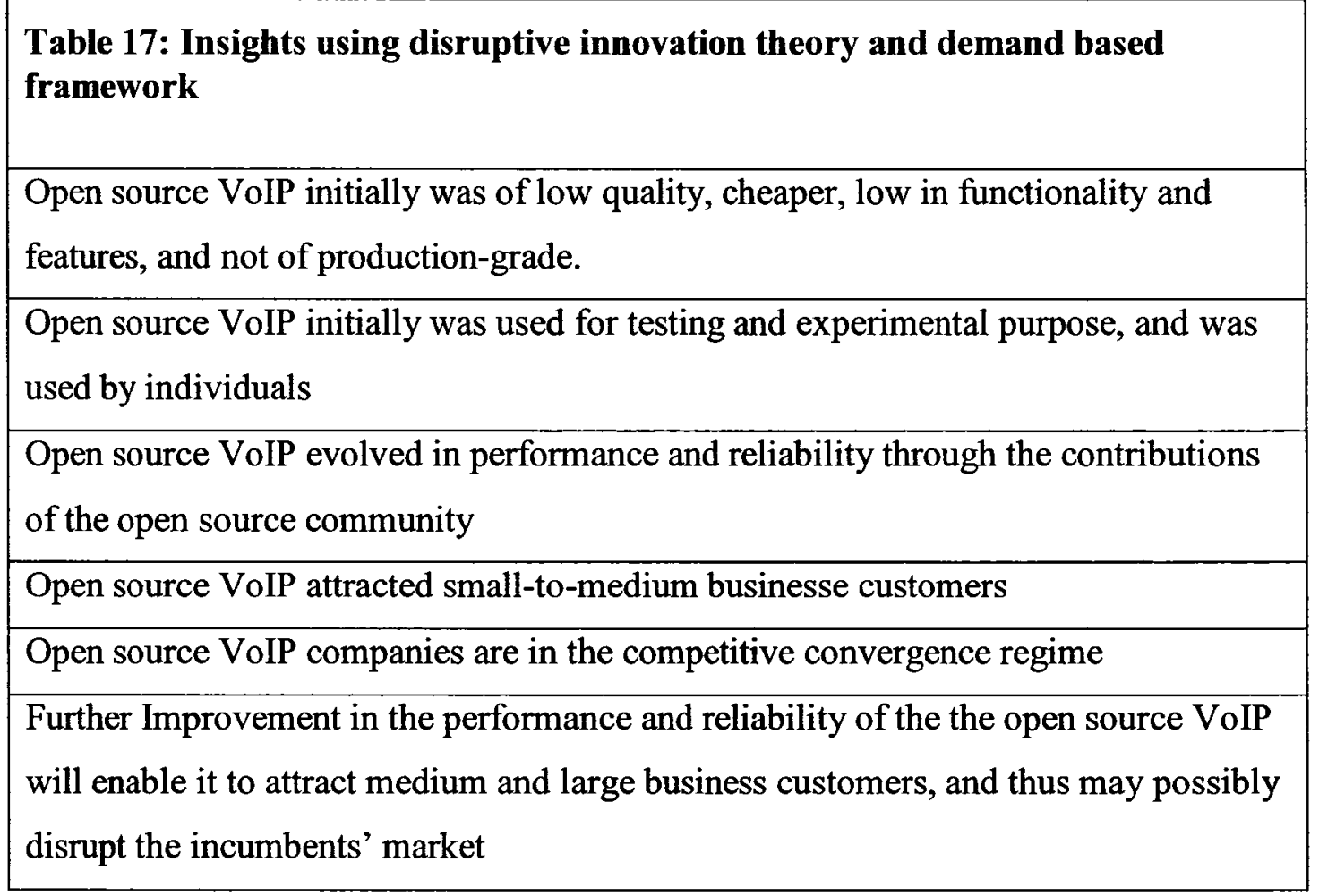

As found in Asterisk case, open source VoIP PBX initially was of low quality, cheaper, and low in functionality and features, and not of production-grade. As a new technology such as VoIP PBX should prove its merits to convince adopters to scrap old system for a new one, the open source VoIP PBX such as Asterisk provided this testing opportunity to small businesses and other non-consumers of PBXs, and by this itself became familiar with the users in the market. Open source VoIP PBX has improved during this testing and transit phase because of the contributions from its users, and is now able to handle small-to-medium enterprises, as evident from the launch of Asterisk business edition in 2005. Open source VoIP PBX companies are now in competitive convergence regime where they compete head-on with proprietary VoIP PBX companies for the same customer segment, the small-to-medium enterprises. The companies 
whose data from write ups, appendices and timeline was used to generate insights are Digium and Pingtel.

Small businesses prefer low costs, while medium and large businesses prefer performance and reliability (Adner, 2001; 2002). As the open source VoIP PBX will improve in these dimensions with time, it will appeal to the medium and large businesses. In that case it will be possible to have further decrease in the total cost of ownership (TCO) of the open source VoIP PBX due to increase in volume of sale and thus attract more and more customers, as per the demand based framework of Adner (2001; 2002).

\subsubsection{Using the lens of Gans and Stern's commercialization framework}

\begin{tabular}{|l|}
\hline Table 18: Insights using Gans and Stern's commercialization framework \\
\hline $\begin{array}{l}\text { Mix of complementary assets and imitability features enable successful open source } \\
\text { VoIP companies to go either for competition or cooperation }\end{array}$ \\
\hline $\begin{array}{l}\text { The most widely used open source license in open source VoIP companies is GPL, } \\
\text { which makes its difficult for incuments to use that code in their products without a } \\
\text { commercial license or acquisition of the open source VoIP company }\end{array}$ \\
\hline $\begin{array}{l}\text { Acquisition of an open source VoIP company may have diverse reasons, such as } \\
\text { ownership of the code and the project, access to a needed user base, or to make the } \\
\text { market favourable for the main products of the acquiring company }\end{array}$
\end{tabular}

As found in all the nine cases, open source VoIP companies are not dependent on the incumbents' complementary assets. They protect their work from imitation through a mix of licensing and branding, as discussed in the write up of digium which got an advantage of strong brand as compared to its fork 'OpenPBX.org'. So based on these complementary assets and 
imitability criteria, open source VoIP businesses can be classified in greenfield competition according to the commercialization framework of the Gans and Stern (2003). So the successful open source VoIP companies can go either for competition or cooperation. These insights apply to all companies in the sample.

The most adopted open source license in open source VoIP companies is GPL. Any modification and derivative work in GPL software must also be made open under GPL. An incumbent who want to use a part of a GPLed OSS in their proprietary solutions can not do so until they also waive control over their own proprietary software, as per the GPL rules of mixing only with other GPL open source software. The hybrid OSS strategies of opening parts and partly open also make it difficult for competitors to use the OSS to compete with its copyright owner. A solution for the incumbent in this situation is either to license the technology from its owner, or to acquire the open source company and its copy righted software. As found in cases, the acquisition of the two open source VoIP companies, Vovida and Equivalence, provides examples.

The acquisition of an open source VoIP company along with its open source project will be motivated by diverse reasons, not only to get the ownership of the code. From the write ups of Vovida Networks and Equivalence, it was found that the their equisitions, Vovida Networks by Cisco and Equivalence by Quicknet, were not intended to generate direct revenue from these open source technologies by Cisco and Quicknet, but to make the market favorable for their own products, i.e. Cisco infrastructure equipment, and Quicknet hardware. The projects started by those acquired companies are still open source and are running. 


\subsubsection{Using the lens of Teece's commercialization framework}

\section{Table 19: Insights using Teece's commercialization frameworks}

OSS lowers development cost and avoids the hazards of contractual agreements for access to complementary assets

OSS allows the company to integrate other OSS functionality without contracting

These insights were generated using Teece's commercialization framework (Teece, 1986; 1988) and the research work of Alam (2006) and using the data of all the nine companies as given in the write ups of companies and appendices.

OSS is a complementary asset, key to the open source VoIP companies' commercialization strategies. As found in all cases, OSS has allowed VoIP companies to lower the product development costs and avoid the hazards of contractual agreements for access to complementary assets. The companies reduce risks of irreversible investments when business relationships anchored around contractual agreements for access to complementary assets does not work out.

\section{$5.4 \quad$ Unexpected results}

Forking issue was found as an unexpected result which can not be explained well by the four theoretical perspectives chosen. Forking destroys some of the competitive advantages of the company which is forked. 


\section{DISCUSSION OF RESULTS}

This chapter answers the research question: How VoIP companies use open source software (OSS).

The research suggests that open source companies in the sample:

- started by targetting individuals who were not PBX consumers

- used open source communities to compete more effectively

- have not created a disruption by displacing incumbents' technology

- enter higher end markets

- do not depend on incumbent's complementary assets

- use dual licenses

- $\quad$ sell complementary products, licenses and services

- $\quad$ protect their own IP within open source environments

\section{Started by targetting individuals who were not $\mathrm{PBX}$ consumers}

As found in Asterisk case, when Asterisk, the first open source VoIP PBX, started in 1999, it was of limited performance. Its main sponsor Digium, being aware of its limitations, targeted only individuals instead of companies, and made profit by selling hardware and providing support services. This period can be marked as competitive isolation regime. Asterisk made possible for Digium to generate revenue which the established companies were not willing to go after. With time Asterisk improved in performance and reliability through the contribution of the 
open source community, and Digium introduced Asterisk business edition for low end of enterprise market in May 2005 and thus entered into the competitive convergence regime.

\section{Used open source communities to compete more effectively}

As discussed in the write up of Pingtel, when it launched VoIP PBX in April 2003, its VoIP PBX was not able to compete with the established VoIP PBX vendors. So it changed its business model, opened the source code in February 2004 and started making profit by selling licenses for its VoIP PBX business edition. Pingtel benefited from this business model given that it benefited customers and the established companies were unwilling to adopt it.

\section{No disruption has been created}

Using disruptive technology and demand based perspectives, this study did not find any disruption in the VoIP PBX market due to open source, a situation when one market player cedes market to the other player, and the market at April 2006 can be characterized as in competitive convergence regime.

\section{Enter higher-end markets}

As found in cases of Digium and Pingtel, for VoIP PBX companies open source version brings the energy and creativity of developers worldwide who accelerate the addition of innovative features and improved integration with other products. The customers of the commercial version of open source VoIP PBX are small to medium businesses at present, but as the product will improve in performance and reliability, it will create an asymmetrical overlap of the consumers

preferences between the segments of the incumbent and entrant, making open source VoIP PBX 
products more appealing to a larger number of customers, as per the demand based framework of Adner $(2001 ; 2002)$.

\section{Do not depend on incumbent's complementary assets}

As found in cases of all nine open source VoIP companies, these companies are not dependent on the incumbents' complementary assets, and get them through the open source projects. They also protect their work from imitation through a mix of licensing and branding, as is the case of Digium against the fork 'OpenPBX.org'. This makes possible for open source VoIP to go either for competition or cooperation with the incumbents. Gans and Stern's commercialization framework advises the same for this type of scenario and classified it in greenfield competition.

Using the Teece's commercialization framework, this study found out that OSS is a complementary asset, key to the open source VoIP companies' commercialization strategies. In all cases, OSS has allowed VoIP companies to lower the product development costs and avoid the hazards of contractual agreements for access to complementary assets.

\section{Use dual licenses}

As found in all nine cases in chapter 4, open source VoIP companies offer dual licenses. On one hand, the open source version brings for the company the advantage of rapid adoption of the software, while on the other hand the commercial version of the same software product brings revenue for the company. They aggregate, integrate and optimize open source components, and test the products for reliability and compatibility. Dual licensing is made possible by accepting 
only those contributions in the open source project which are disclaimed by their original authors.

\section{Sell complementary products, licenses and services}

As found in cases of Digium and Voicetronix, these VoIP companies appropriate returns through selling of complementary assets such as hardware. All cases in the study suggest that these companies also provide services such as consultancy, support and training, and license code outside of the GPL for use in proprietary applications.

\section{Protect their IP within open source environments}

VoIP PBX companies, Pingtel and Digium, claim that commercial version is based entirely on the same OSS available from the open source communities, and the value has been created by packaging. Commercial version is provided in binaries only and its use is granted for an annual fee. To protect the commercial version of software against piracy, various methods are used, such as providing it in binary code only, and using company's trademarks in the software. Being the copyright owner of the software, Digium and Pingtel can offer commercial version of their VoIP PBX under any license and can mix it with any type of software; however they claim that their commercial versions are based entirely on the same GPLed software whose source code is available from the open source communities (cases of Digium and Pingtel). They claim so for marketing purpose to be seen as a company with pure open source products and to retain the trust of their customers and open source community. 


\section{RESEARCH}

\subsection{Conclusions}

The objective of this research was to answer the question: How companies use OSS to capture value in the VoIP market. To answer this question, four theoretical perspectives were used to examine data on nine open source companies.

This research found out that the open source VoIP companies started from the niche market of nonconsumption and are in the competitve convergence regime at present. Successful open source VoIP companies can go either for the competiton or cooperation as per the Gans and Stern framework. OSS lowers development costs of the open source VoIP companies. Table 20 summarizes the insights using the four perspectives:

\begin{tabular}{|l|l|}
\hline \multicolumn{2}{|l|}{ Table 20: Insights using four theoretical perspectives } \\
\hline Theoretical Perspective & Insights \\
\hline Disruptive innovation & $\begin{array}{r}\text { 1. Open source VoIP initially was of low quality, cheaper, low in } \\
\text { functionality and features, and not of production-grade. } \\
\text { 2. Open source VoIP initially was used for testing and experimental } \\
\text { purpose, and was used by individuals } \\
\text { 3. Open source VoIP evolved in performance and reliability through } \\
\text { the contributions of the open source community } \\
\text { Open source VoIP attracted small-to-medium businesse customers }\end{array}$ \\
\end{tabular}




\begin{tabular}{|c|c|}
\hline $\begin{array}{l}\text { Adner's demand based } \\
\text { framework }\end{array}$ & $\begin{array}{l}\text { 1. Open source VoIP compnanies are in the competitive convergence } \\
\text { regime } \\
\text { 2. Improvement in the performance and reliability of the the open } \\
\text { source VoIP will enable it to attract medium and large business } \\
\text { customers, and thus may possiblity disrupt the incumbents' market }\end{array}$ \\
\hline $\begin{array}{l}\text { Gans and Stern's } \\
\text { commercialization } \\
\text { framework }\end{array}$ & $\begin{array}{l}\text { 1. Mix of complementary assets and imitability features enable } \\
\text { successful open source VoIP companies to go either for } \\
\text { competition or cooperation } \\
\text { 2. The most widely used open source license in open source VoIP } \\
\text { companies is GPL, which makes its difficult for incuments to use } \\
\text { that code in their products without a commercial license or } \\
\text { acquisition of the open source VoIP company. } \\
\text { 3. Acquisition of an open source VoIP company may have diverse } \\
\text { reasons, such as ownership of the code and the project, access to a } \\
\text { needed user base, or to make the market favourable for the main } \\
\text { products of the acquiring company }\end{array}$ \\
\hline $\begin{array}{l}\text { Teece's } \\
\text { commercialization } \\
\text { framework }\end{array}$ & $\begin{array}{l}\text { 1. OSS lowers development cost and avoids the hazards of } \\
\text { contractual agreements for access to complementary assets } \\
\text { 2. OSS allows the company to integrate other OSS functionality } \\
\text { without contracting }\end{array}$ \\
\hline
\end{tabular}

The results suggest that open source VolP companies try to get high adoption of their products through open source software, and appropriate returns through selling of packaged and commercial version of software and complementary assets and services. The services surrounding software products range from consulting, implementation, support, and training to application management. OSS pushes these companies up in the value chain. Nine of the nine companies in the sample have dual licenses. 
This study contributes write ups of nine open source VoIP companies, timeline for the major events in the open source VoIP market, and insights from using four theoretical perspectives to examine the data

\subsection{Limitations}

This study has at least two limitations. The first limitation is that this research only used secondary materials available on the Web and did not interview company employees. Thus, we cannot make statement about sources of error and bias.

The second limitation is due to the fact that open source VoIP commercialization is still a relatively new phenomenon, and the number of companies that can be studied is not large. All known open source VoIP companies were included in this study.

\subsection{Suggestions for future research}

Two suggestions for future research are proposed. First, this study can be redone using primary data from companies' executives.

Second, this research can be undertaken in other domains to examine the generalizability of the results reported in this research on how companies use OSS to capture value. 


\section{REFERENCES}

Adner, R. 2002. When are technologies disruptive? A demand based view of the emergence of competition. Strategic Management Journal, 23(8): 667-688.

Adner, R. and Zemsky, P. 2001. Disruptive Technologies and the Emergence of Competition. INSEAD Working paper 2001/103/SM.

\footnotetext{
Alam, R. 2006. Open source software projects, market offers, and competitive advantage, Master's thesis, Carleton University, Ottawa.
}

Bonaccorsi, A. and Rossi, C. 2003. Why open source software can succeed. Research Policy, 32(7): $1243-1258$.

Bonaccorsi, A. and Rossi, C. 2004. Comparing motivations of individual programmers and firms to take part in the open source movement. From community to business.

http://opensource.mit.edu/papers/bnaccorsirossimotivationlong.pdf. Accessed November 10, 2005).

Bonaccorsi, A., Rossi, C. and Giannangeli, S. 2004. Adaptive entry strategies under dominant standards - Hybrid business models in the open source software industry. Social Science Research Network (SSRN), Working paper. Available at: http://papers.ssrn.com/sol3/papers.cfm?abstract_id=519842. Accessed January 25, 2006.

Bower, J.L. and Christensen, C.M. 1995. Disruptive technologies: Catching the next wave. Harvard Business Review, 73(1): 43-53. 
Chesbrough, H.W. and Rosenbloom, R.S. 2002. The role of business models in capturing value from innovation: Evidence from Xerox Corporation's spin-off companies. Industrial and corporate change, 11(3): 529-555.

Cosby, S. and Hogstrom, M. 2005. Leveraging open source in your application infrastructure: Apache Geronimo and WebSphere community edition. IBM webcast, $16^{\text {th }}$ November. https://www14.software.ibm.com/webapp/iwm/web/preLogin.do?source=dw-cwcsdp\&S PKG $=111605$

Christensen, C.M., Scott D.A. and Erik A.R.. 2004. Seeing what's next?: Using the theories of innovation to predict industry change. Boston, MA: Harvard Business School Press.

Christensen, C.M. and Raynor, M.E. 2003. The innovator's solution: Using good theory to solve the dilemmas of growth. Boston, MA: Harvard Business School Press.

Christensen, C.M., Johnson M.W. and Rigby D.K. 2002. Foundations for growth - How to identify and build disruptive new businesses. MIT Sloan Management Review, Spring 2002: 2231.

Christensen, C.M., Raynor, M.E. and Verlinden, M. 2001. Skate to where the money will be. Harvard Business Review, November: 72-81. 
Christensen, C.M. and Overdorf M. 2000. Meeting the challenge of disruptive change. Harvard Business Review, 78(2): 66-76.

Christensen, C.M. 1997. The innovator's dilemma. Boston, MA: Harvard Business School Press.

Dahlander, L. 2004. Appropriating the commons: Companies in open source software. Working paper. Available at: http://opensource.mit.edu/papers/dahlander2.pdf. Accessed November 11, 2005.

Dahlander, L. and Magnusson, M. 2005. Relationships between open source software companies and communities: Observations from Nordic firms. Research Policy, 34: 481-493.

Drew, P. and Gallon, C. 2003. Next-generation VoIP network architecture. Multiservice switching forum. http://msforum.org/techinfo/reports.shtml. Accessed May 26, 2005.

Eisenhardt, K.M. 1989. Building theories from case study research. Academy of Management Review, 14(4): 532-550.

Franck, E. and Jungwirth, C. 2003. Reconciling rent-seekers and donators: The governance structure of open source. Journal of Management and Governance, 7(4): 401

Franke, N. and Von Hippel, E. 2003. Satisfying heterogeneous user needs via innovation toolkits: The case of apache security software. Research Policy, 32(7): 1199-1215. 
Gans, J.S. and Stern, S. 2003. The product market and the market for "ideas":

Commercialization strategies for technology entrepreneurs. Research Policy, 32(2): 333-350.

Gans, J.S., Hsu, D.H. and Stern, S. 2002. When does start-up innovation spur the gale of creative destruction? RAND Journal of Economics, 33(4): 571-586.

Goth, G. 2005. Open source meets venture capital. IEEE Distributed Systems Online, 6(6).

Goth, G. 2005. Open source infrastructure solidifying quickly. IEEE Distributed Systems Online, $6(6)$

Hagel, J. and Brown, J.S. 2005. Finding new sources of strategic advantage. Working Knowledge online newsletter of HBS. http://hbswk.hbs.edu/item.jhtml?id=4778\&t=strategy. Accessed January 04, 2006.

Hapgood, F. 2001. Using unix. http://www.cio.com/archive/100101/et revisit.html. Accessed December 10, 2005.

Hars, A. and Ou, S. 2002. Working for free? Motivations for participating in open source projects. International Journal of Electronic Commerce, 25-39.

Hecker, F. 2000. Setting up shop: the business of Open-Source software. http://www.hecker.org/writings/setting-up-shop.html. Accessed February 12, 2006. 
Henkel, J. 2003. Open source software from commercial firms - Tools, complements, and collective invention. http://www.inno-tec.bwl.unimuenchen.de/forschung/henkel/OSS_JHenkel_2003-05.pdf. Accessed October 9, 2005.

Henkel, J. 2004. Patterns of free revealing - Balancing code sharing and protection in commercial open source development. http://opensource.mit.edu/papers/henkel2.pdf. Accessed December 17, 2005.

Hertel, G., Niedner, S. and Herrmann, S. 2003. Motivation of software developers in the open source projects: An Internet-based survey of contributors to the Linux kernel. Research Policy, 32(7): 1159-1177.

Keating, T. 2001. In search of a Linux based PBX.

http://www.tmcnet.com/comsol/1101/1101cc.htm. Accessed May 26, 2005.

Koening, J. 2004. Seven open source business strategies for competitive advantage. IT Manager's Journal, http://management.itmanagersjournal.com/management/04/05/10/2052216.shtml?tid=85 Accessed May 16, 2005.

Krishnamurthy, S. 2002. Cave or community? An empirical examination of 100 mature open source projects. http://www.firstmonday.org/issues/issue7 6/krishnamurthy. Accessed December $23,2005)$.

Krogh, G.V. and Hippel, E.V. 2003. Special issue on open source software development. Research Policy, 32(7): 1149-1157. 
Lakhani, K. and von Hippel, E. 2003. How open source software works: "Free" user-to-user assistance. Research Policy, 32(6): 923-943.

Lerner, J. and Tirole, J. 2001. The open source movement: Key research questions. European Economic Review, 45: 819-826.

Lerner, J. and Tirole, J. 2002. The scope of open source licensing. MIT working paper, http://opensource.mit.edu/papers/lernertirole2.pdf. Accessed October 03, 2005.

Magretta, J. 2002. Why business models matter? Harvard Business Review, 80(5): 86-92.

Mills, E. 2005. Yahoo, Microsoft join IM hands. News.com, http://news.com.com/Yahoo\%2C+Microsoft+join+IM+hands/2100-10255893802.html?part=dht\&tag=ntop\&tag=nl.e433. Accessed November 13, 2005.

Mohney, D. 2005. Open source. VON Magazine, http://www.vonmag.com/issue/2005/oct/depts/category_killers.asp. Accesses November 13, 2005.

Nissila, J. 2004. Towards better understanding of open source business models. http://w3.msi.vxu.se/users/per/IRIS27/iris27-1202.pdf. Accessed December 06, 2005.

O'Mahony, S. 2003. Guarding the commons: How community managed projects protect their work. Research Policy, 32(7): 1179-1198. 
Open source initiative. 1998. http://www.opensource.org. Accessed September 27, 2005.

Pal, N. and Madanmohan, T.R. 2002. Competing on open source: Strategies and practice. http://opensource.mit.edu/papers/madanmohan.pdf. Accessed December 22, 2005.

Paulson, J., Succi, G. and Eberlein, A. 2004. An empirical study of open-source and closedsource software products. IEEE Transaction on Software Engineering, 30(4): 246-256.

Peng, Z. 2004. Linux adoption by companies. MIT Free/Open Source Research Community, http://opensource.mit.edu/papers/peng.pdf. Accessed June 16, 2005.

Raymond, E.S. 1999a. The Magic cauldron. http:/www.catb.org/ esr/writings/magiccauldron/magic-cauldron.html. Accessed September 20, 2005.

Raymond, E.S, 1999b. The cathedral and the bazaar. O'Reilly and Associates, Sebastpol, CA. Raymond, E.S. 1999c. Halloween I: Annotated version. http://www.opensource.org/halloween/halloween1.php. Accessed October 2, 2005.

Reynolds, B. 2002. Enabling secure IP telephony in enterprise networks. Unpublished master dissertation, University of California, Davis. 
Rugullies, E., Moore, C. and Fossner, L. 2005. Open source collaboration platforms: Give it five more years. Research report, Forrester Research, Inc.

Schuk, C. 2005. Open-source PBX battle brewing. http://voxilla.com/voxstory136.html. Accessed May 26, 2005.

Schwarz, B. 2004. Asterisk open-source PBX system. Linux Journal, 2004(118).

Shankland, S. 2005. Google throws bodies at OpenOffice. News.com, http://news.com.com/Google+throws+bodies+at+OpenOffice/2100-73445920762.html?part=dht\&tag=ntop\&tag-nl.e703. Accessed November 13, 2005.

Spiller, D. and Wichmann, T. 2002. Basics of open source software markets and business models. Berlecon Research GmbH. http://www.infonomics.nl/FLOSS/report/index.htm. Accessed November 25, 2005.

Stern, H., Phipps, S. and Hahn, S. 2006. Open community: OpenSolaris, open source and the future of software. Sun Net Talk on Demand, https://communications.sun.com/dialog/ondemandcatalog.do?cid=15781\#1. Accessed January $28,2006$.

Sugar, D. 2002. GNU Bayonne is for telephony. Linux Journal, 2002(100): 10. 
Sulkin, A. 2002. PBX systems for IP telephony: Migrating enterprise communications. USA: McGraw-Hill Companies Inc.

Teece, D.J., Pisano, G. and Shuen, A. 1997. Dynamic capabilities and strategic management. Strategic Management Journal, 18(7): 509-533.

Teece, D.J. 1986. Profiting from technological innovation: Implications for integration, collaboration, licensing, and public policy. Research Policy, 15: 285-305.

Teece, D.J. 1988. Capturing value from technological innovation: integration, strategic partnering, and licensing decisions. Interfaces, 18(3), 46-61.

Timmers, P. 1998. Business models for E-commerce. Electronic Markets, 8: 3-7.

Von Hippel, E. and Von Krogh, G. 2003. Open source software and the "private-collective" innovation model: Issues for organization science. Organization Science, 14(2): 209.

Weill, P., Malone, T., D’Urso, V., Herman, G. and Woerner, S. 2004. Do some business models perform better than others? A study of the 1000 largest US firms. Working paper, MIT Sloan School of Management, Cambridge, MA.

West, J. 2003. How open is open enough? Melding proprietary and open source platform strategies. Research Policy, 32: 1259-1285. 
West, J. and Gallagher, S. 2004. Key challenges of open innovation: Lessons from open source software. http://www.cob.sjsu.edu/west j/Papers/WestGallagher2004.pdf. Accessed October 2, 2005.

West, J. and O’Mahony, S. 2005. Contrasting community building in sponsored and community founded open source projects. http://opensource.mit.edu/papers/westomahony.pdf. Accessed September 15, 2005.

Wheeler, D.A., 2005. Why open source software/free software (OSS/FS, FLOSS, or FOSS)? Look at the numbers! http://www.dwheeler.com/oss fs why.html. Accessed January 15, 2006.

Wichmann, T. 2002. FLOSS final report - Part 2: Free/Libre open source software: Survey and study - Firms' open source activities: Motivations and policy implications. Berlecon Research. http://www.berlecon.de/studien/downloads/200207FLOSS_Activities.pdf. Accessed September $\underline{16}, 2005$.

Wilcox, J. 2000. IBM to spend \$1 billion on Linux in 2001. CNET News.com. http:news.cnet.com/news/0-1003-200-4111945.html. Accessed October 5, 2005.

Zhen, W. 2004. Using Christensen's models to make sense of changes in the Chinese telecommunications equipment supplier industry. Master's thesis, Carleton University, Ottawa. 


\section{APPENDICES}

Appendix A: Software licenses overview

\begin{tabular}{|l|l|l|l|l|l|l|l|}
\hline $\begin{array}{l}\text { Software } \\
\text { license }\end{array}$ & $\begin{array}{l}\text { Available } \\
\text { at no cost }\end{array}$ & $\begin{array}{l}\text { Distribution } \\
\text { allowed }\end{array}$ & $\begin{array}{l}\text { No usage } \\
\text { restrictions }\end{array}$ & $\begin{array}{l}\text { Source } \\
\text { code freely } \\
\text { available } \\
\text { modification } \\
\text { allowed } \\
\text { work must } \\
\text { be free } \\
\text { again }\end{array}$ & $\begin{array}{l}\text { Source code } \\
\text { with } \\
\text { proprietary } \\
\text { software } \\
\text { allowed }\end{array}$ \\
\hline $\begin{array}{l}\text { Public } \\
\text { Domain }\end{array}$ & $\mathrm{x}$ & $\mathrm{x}$ & $\mathrm{x}$ & $\mathrm{x}$ & $\mathrm{x}$ & & $\mathrm{x}$ \\
\hline Shareware & $\mathrm{x}) 1$ & $\mathrm{x}$ & & & & & \\
\hline Freeware & $\mathrm{x}$ & $\mathrm{x}$ & $\mathrm{x}$ & & & & \\
\hline GPL & $\mathrm{x}$ & $\mathrm{x}$ & $\mathrm{x}$ & $\mathrm{x}$ & $\mathrm{x}$ & $\mathrm{x}$ & \\
\hline LGPL & $\mathrm{x}$ & $\mathrm{x}$ & $\mathrm{x}$ & $\mathrm{x}$ & $\mathrm{x}$ & $\mathrm{x}$ & $\mathrm{x}$ \\
\hline MPL & $\mathrm{x}$ & $\mathrm{x}$ & $\mathrm{x}$ & $\mathrm{x}$ & $\mathrm{x}$ & $\mathrm{x}$ & $\mathrm{x}$ \\
\hline BSD-License & $\mathrm{x}$ & $\mathrm{x}$ & $\mathrm{x}$ & $\mathrm{x}$ & $\mathrm{x}$ & & $\mathrm{x}$ \\
\hline
\end{tabular}

1) Shareware is gratis for a trial period only

Source: Nissila (2004)

Appendix B: Background information of the open source VoIP companies

\begin{tabular}{|c|c|c|c|c|}
\hline $\begin{array}{l}\text { Distinguishing } \\
\text { dimension }\end{array}$ & Pingtel Corp. & Digium Inc. & Voicetronix & Null Team \\
\hline $\begin{array}{l}\text { Year company was } \\
\text { founded }\end{array}$ & 1999 & 1999 & 1995 & 2004 \\
\hline $\begin{array}{l}\text { Country where } \\
\text { company was } \\
\text { founded }\end{array}$ & $\overline{\text { USA }}$ & USA & Australia & Romania \\
\hline $\begin{array}{l}\text { Country where } \\
\text { company operates }\end{array}$ & USA & USA & Australia & Europe \\
\hline $\begin{array}{l}\text { Birth of the } \\
\text { company }\end{array}$ & $\begin{array}{l}\text { From proprietary to } \\
\text { open source }\end{array}$ & $\begin{array}{l}\text { Born as open } \\
\text { source }\end{array}$ & $\begin{array}{l}\text { Were a hardware } \\
\text { company. Later on } \\
\text { developed OSS } \\
\text { telephony products }\end{array}$ & $\begin{array}{l}\text { Born as open } \\
\text { source }\end{array}$ \\
\hline Product market & $\begin{array}{l}\text { VoIP PBX + built-in } \\
\text { IVR, softphone, and } \\
\text { call manager }\end{array}$ & $\begin{array}{l}\text { TDM/VoIP } \\
\text { PBX + Built in } \\
\text { IVR Server }\end{array}$ & $\begin{array}{l}\text { TDM PBX (work } \\
\text { on VoIP) } \\
\text { and Telephony } \\
\text { application server }\end{array}$ & $\begin{array}{l}\text { Softswitch } \\
\text { (Telephony } \\
\text { Engine) }\end{array}$ \\
\hline $\begin{array}{l}\text { TMT as of } \\
\text { September } 2005\end{array}$ & $\begin{array}{l}\text { Professionals who } \\
\text { did not create the } \\
\text { open source project }\end{array}$ & $\begin{array}{l}\text { CEO=Founder } \\
\text { of open source } \\
\text { project } \\
\text { =Founder of the } \\
\text { company }\end{array}$ & $\begin{array}{l}\text { CEO=one of the } \\
\text { several founders of } \\
\text { the company and } \\
\text { the project }\end{array}$ & $\begin{array}{l}\text { Founders of the } \\
\text { company are also } \\
\text { the founders of } \\
\text { project }\end{array}$ \\
\hline $\begin{array}{l}\text { Number of } \\
\text { employees }\end{array}$ & $\mathrm{N} / \mathrm{A}$ & $40+$ & N/A & N/A \\
\hline $\begin{array}{l}\text { Obtained VC } \\
\text { funding }\end{array}$ & No & No & No & No \\
\hline
\end{tabular}




\begin{tabular}{|l|l|l|l|l|}
\hline OSS & $\begin{array}{l}\text { sipX, sipXphone, } \\
\text { sipXezPhone, }\end{array}$ & Asterisk & $\begin{array}{l}\text { OpenPBX and } \\
\text { CTserver } \\
\text { (Cards also support } \\
\text { Asterisk, Bayonne, } \\
\text { etc.) }\end{array}$ & $\begin{array}{l}\text { YATE (Yet Another } \\
\text { Telephony Engine) }\end{array}$ \\
\hline $\begin{array}{l}\text { Open source } \\
\text { license }\end{array}$ & LGPL & GPL & GPL & GPL \\
\hline $\begin{array}{l}\text { Year open source } \\
\text { project was set up }\end{array}$ & 2004 & 1999 & N/A & 2004 \\
\hline $\begin{array}{l}\text { Sponsors of open } \\
\text { source projects }\end{array}$ & $\begin{array}{l}\text { Company is one of } 8 \\
\text { partners that set up } \\
\text { the non-for-profit } \\
\text { foundation } \\
\text { responsible for open } \\
\text { source projects }\end{array}$ & $\begin{array}{l}\text { Company has } \\
\text { set up all } \\
\text { projects }\end{array}$ & $\begin{array}{l}\text { Company has set } \\
\text { up all projects }\end{array}$ & $\begin{array}{l}\text { Company has set } \\
\text { up all projects }\end{array}$ \\
\hline $\begin{array}{l}\text { Number of } \\
\text { developers }\end{array}$ & N/A & N/A & N/A & N/A \\
\hline Number of \\
Opnloads
\end{tabular}

\begin{tabular}{|c|c|c|c|c|c|}
\hline $\begin{array}{l}\text { Distinguishing } \\
\text { dimension }\end{array}$ & Tycho Softworks & iptel.org & $\begin{array}{l}\text { Vovida Networks } \\
\text { (acquired by } \\
\text { Cisco in 2000) }\end{array}$ & $\begin{array}{l}\text { Equivalence Pty } \\
\text { Ltd. (acquired by } \\
\text { Quicknet } \\
\text { Technologies Inc. } \\
\text { USA in 2000) }\end{array}$ & Antisip \\
\hline $\begin{array}{l}\text { Year company } \\
\text { was founded }\end{array}$ & 2005 & 2002 & 1999 & 1996 & 2005 \\
\hline $\begin{array}{l}\text { Country where } \\
\text { company was } \\
\text { founded }\end{array}$ & USA & Germany & USA & Australia & France \\
\hline $\begin{array}{l}\text { Country where } \\
\text { company operates }\end{array}$ & USA & Germany & $\overline{\text { USA }}$ & Australia & France \\
\hline $\begin{array}{l}\text { Birth of the } \\
\text { company }\end{array}$ & $\begin{array}{l}\text { Born as open } \\
\text { source }\end{array}$ & $\begin{array}{l}\text { Born as open } \\
\text { source }\end{array}$ & $\begin{array}{l}\text { Born as open } \\
\text { source }\end{array}$ & $\begin{array}{l}\text { proprietary to } \\
\text { open source }\end{array}$ & $\begin{array}{l}\text { Born as open } \\
\text { source }\end{array}$ \\
\hline Product market & $\begin{array}{l}\text { Telephony } \\
\text { application } \\
\text { server (IVR } \\
\text { Platform) }\end{array}$ & SIP Server & $\begin{array}{l}\text { Telephony } \\
\text { application server, } \\
\text { and SIP, MGCP, } \\
\text { RTP and H.323 } \\
\text { Annex F protocol } \\
\text { stacks }\end{array}$ & $\begin{array}{l}\text { Open source } \\
\text { H.323 stack }\end{array}$ & $\begin{array}{l}\text { Open source } \\
\text { SIP stack }\end{array}$ \\
\hline $\begin{array}{l}\text { TMT as of } \\
\text { September } 2005\end{array}$ & $\begin{array}{l}\text { CEO=one of the } \\
\text { founders of open } \\
\text { source project } \\
=\text { Founder of the } \\
\text { company }\end{array}$ & $\begin{array}{l}\text { iptel.org is } \\
\text { offshoot of GMD } \\
\text { Focus to mainly } \\
\text { look after the } \\
\text { SER project and } \\
\text { business }\end{array}$ & $\begin{array}{l}\mathrm{CEO}=\text { one of the } \\
\text { two founders of } \\
\text { open source } \\
\text { project and the } \\
\text { company }\end{array}$ & $\begin{array}{l}\mathrm{CEO}=\text { one of the } \\
\text { two founders of } \\
\text { open source } \\
\text { project and the } \\
\text { company }\end{array}$ & $\begin{array}{l}\text { Aymeric } \\
\text { Moizard is the } \\
\text { founder of the } \\
\text { open source } \\
\text { project and the } \\
\text { company }\end{array}$ \\
\hline $\begin{array}{l}\text { Number of } \\
\text { employees }\end{array}$ & N/A & N/A & 65 & N/A & $\mathrm{N} / \mathrm{A}$ \\
\hline
\end{tabular}

${ }^{6}$ YATE's license is GPL with an exception for linking with OpenH323 and PWlib (licensed under MPL) 


\begin{tabular}{|c|c|c|c|c|c|}
\hline $\begin{array}{l}\text { Obtained VC } \\
\text { funding }\end{array}$ & No & No & No & No & No \\
\hline OSS & GNU Bayonne 2 & $\begin{array}{l}\text { SIP Express } \\
\text { Router (SER) }\end{array}$ & $\begin{array}{l}\text { VOCAL library } \\
\text { and VoIP protocol } \\
\text { stacks }\end{array}$ & OpenH323 & oSIP \\
\hline $\begin{array}{l}\text { Open source } \\
\text { license }\end{array}$ & GPL & GPL & $\begin{array}{l}\text { Vovida Software } \\
\text { License, Version } \\
1.0\end{array}$ & MPL & LGPL \\
\hline $\begin{array}{l}\text { Year open source } \\
\text { project was set up }\end{array}$ & 1998 & 2002 & 1999 & 1998 & 2000 \\
\hline $\begin{array}{l}\text { Sponsors of open } \\
\text { source projects }\end{array}$ & $\begin{array}{l}\text { Owner of Tycho } \\
\text { Softworks, } \\
\text { David Sugar, is } \\
\text { one of the main } \\
\text { authors and } \\
\text { founders of the } \\
\text { open source } \\
\text { project }\end{array}$ & $\begin{array}{l}\text { Company has set } \\
\text { up all projects }\end{array}$ & $\begin{array}{l}\text { Company has set } \\
\text { up all projects }\end{array}$ & $\begin{array}{l}\text { Company has set } \\
\text { up all projects }\end{array}$ & $\begin{array}{l}\text { Company has } \\
\text { set up all } \\
\text { projects }\end{array}$ \\
\hline $\begin{array}{l}\text { Number of } \\
\text { developers }\end{array}$ & N/A & $\begin{array}{l}\text { Main work was } \\
\text { done by about } 13 \\
\text { developers }\end{array}$ & 65 & $\mathrm{~N} / \mathrm{A}$ & $\mathrm{N} / \mathrm{A}$ \\
\hline $\begin{array}{l}\text { Number of } \\
\text { downloads }\end{array}$ & N/A & N/A & N/A & N/A & N/A \\
\hline $\begin{array}{l}\text { Open source } \\
\text { communities }\end{array}$ & $\begin{array}{l}\text { Gnutelephony.or } \\
\mathrm{g}\end{array}$ & $\begin{array}{l}\text { http://developer. } \\
\text { berlios.de/project } \\
\text { s/ser/ }\end{array}$ & vovida.org/ & openh323.org & $\begin{array}{l}\text { gnu.org/softwa } \\
\text { re/osip }\end{array}$ \\
\hline
\end{tabular}

Appendix C: Business models of open source VoIP companies

\begin{tabular}{|l|l|}
\hline Company & Business models \\
\hline Digium & $\begin{array}{l}\text { 1. Sale of licenses for Asterisk business edition (Packaging) } \\
\text { 3. Sale of Asterisk licensing outside of the GPL for use in proprietary } \\
\text { applications (Dual licensing) } \\
\text { 4. Consulting and support services }\end{array}$ \\
\hline Pingtel & $\begin{array}{l}\text { 1. Sale of licenses for SIPxchange VoIP PBX } \\
\text { 2. Support and service provisioning on fee }\end{array}$ \\
\hline Voicetronix & $\begin{array}{l}\text { Sale of hardware required for open source PBXs OpenPBX and Asterisk } \\
\text { and the application servers CT server and Bayonne }\end{array}$ \\
\hline
\end{tabular}




\begin{tabular}{|l|l|}
\hline Null Team & Consulting services for YATE softswitch, and sell solutions for call \\
centers, telephony carriers, enterprises and soho market \\
\hline Sycho & Consulting services for Bayonne to make IVR applications \\
Support services for Bayonne
\end{tabular}

Appendix D: Open source VoIP companies by the license of the open source projects they set up

\begin{tabular}{|l|l|c|c|}
\hline $\begin{array}{l}\text { License of the open source } \\
\text { project }\end{array}$ & $\begin{array}{l}\text { Companies that set up the } \\
\text { license }\end{array}$ & $\begin{array}{l}\text { Number of } \\
\text { companies } \\
\text { that set up } \\
\text { the license }\end{array}$ & $\begin{array}{c}\text { Percentage } \\
\text { of sample }\end{array}$ \\
\hline GPL & $\begin{array}{l}\text { Digium, Voicetronix, Null } \\
\text { Team, Tycho Softworks, } \\
\text { iptel.org }\end{array}$ & 5 & $56 \%$ \\
\hline LGPL & Pingtel, Antisip & 2 & $22 \%$ \\
\hline MPL & Equivalence & 1 & $11 \%$ \\
\hline Vovida Software License & Vovida Networks & 1 & $11 \%$ \\
\hline & & 9 & 100 \\
\hline
\end{tabular}

